\title{
An isopycnic ocean carbon cycle model
}

\author{
K. M. Assmann ${ }^{1}$, M. Bentsen ${ }^{2,1}$, J. Segschneider ${ }^{3}$, and C. Heinze ${ }^{4,1}$ \\ ${ }^{1}$ Bjerknes Centre for Climate Research, Bergen, Norway \\ ${ }^{2}$ Nansen Remote Sensing and Environmental Research Centre, Bergen, Norway \\ ${ }^{3}$ Max-Planck Institute for Meteorology, Hamburg, Germany \\ ${ }^{4}$ Geophysical Institute, University of Bergen, Bergen, Norway
}

Received: 1 July 2009 - Published in Geosci. Model Dev. Discuss.: 27 July 2009

Revised: 13 November 2009 - Accepted: 2 December 2009 - Published: 16 February 2010

\begin{abstract}
The carbon cycle is a major forcing component in the global climate system. Modelling studies, aiming to explain recent and past climatic changes and to project future ones, increasingly include the interaction between the physical and biogeochemical systems. Their ocean components are generally z-coordinate models that are conceptually easy to use but that employ a vertical coordinate that is alien to the real ocean structure. Here, we present first results from a newly-developed isopycnic carbon cycle model and demonstrate the viability of using an isopycnic physical component for this purpose. As expected, the model represents well the interior ocean transport of biogeochemical tracers and produces realistic tracer distributions. Difficulties in employing a purely isopycnic coordinate lie mainly in the treatment of the surface boundary layer which is often represented by a bulk mixed layer. The most significant adjustments of the ocean biogeochemistry model HAMOCC, for use with an isopycnic coordinate, were in the representation of upper ocean biological production. We present a series of sensitivity studies exploring the effect of changes in biogeochemical and physical processes on export production and nutrient distribution. Apart from giving us pointers for further model development, they highlight the importance of preformed nutrient distributions in the Southern Ocean for global nutrient distributions. The sensitivity studies show that iron limitation for biological particle production, the treatment of light penetration for biological production, and the role of diapycnal mixing result in significant changes of nutrient distributions and liniting factors of biological production.
\end{abstract}

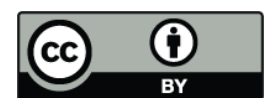

Correspondence to: K. M. Assmann (karen.assmann@bjerknes.uib.no)

\section{Introduction}

The human induced increase of atmospheric greenhouse gases, especially that of $\mathrm{CO}_{2}$, has led to growing concern about the climatic and environmental consequences related to these perturbations. The ocean plays an important role in the regulation of atmospheric gases (e.g., Sillen, 1966). It is known to represent the major ultimate sink for anthropogenic $\mathrm{CO}_{2}$ (e.g., Bolin and Eriksson, 1957; Archer, 2005) due to its centennial turnover time scale (Matsumoto et al., 2007) and its high buffer capacity for $\mathrm{CO}_{2}$ additions (Buch et al., 1932; Revelle and Suess, 1957). For correct predictions of the development of the Earth's carbon budget during the coming decades and centuries under given greenhouse gas emission scenarios, the kinetics of marine $\mathrm{CO}_{2}$ uptake from the atmosphere play a crucial role: How quickly can the ocean neutralise $\mathrm{CO}_{2}$ additions to the atmosphere through input from fossil fuel burning and cement manufacturing (Boden et al., 2009) as well as land use (Houghton, 1999)? Further, in recent years, carbon cycle climate feedbacks have been identified to provide a major uncertainty in future projections of climate change (Denman et al., 2007). It is likely that these feedbacks will reinforce climate change, but feedback strength varies considerably among different model systems (Friedlingstein et al., 2006).

While quantifying the regulation of the Earth's radiative budget is a key question, we require coupled physicalbiogeochemical ocean models to address a number of additional important issues. The rising carbon content of the ocean causes a drop in $\mathrm{pH}$ (ocean acidification) with potentially severe impacts for marine biota and related geochemical cycles (Caldeira and Wickett, 2003; Raven et al., 2005). The $\mathrm{pH}$ changes have to be predicted appropriately with respect to space and time and impacts such as metal speciation on biogeochemical cycling have to be quantified and upscaled to the Earth system. Global nutrient cycling is undergoing significant changes (Duce et al., 2008) with

Published by Copernicus Publications on behalf of the European Geosciences Union. 
poor established consequences for ocean biogeochemistry. Trace metal delivery to the ocean may change due to climatic change, especially for iron, a biolimiting micronutrient (Jickells et al., 2005). Further concerns are the growing areas of poorly ventilated water masses in the oceans and decreasing oxygen water column levels on a large scale (e.g., Whitney et al., 2007; Oschlies et al., 2008).

So far, only a relatively small number of global interactive carbon cycle climate models ("Earth system models", to be extended also with respect to other processes and cycles) exist. The ocean components in these systems for ocean physics (velocity field, density field and sea ice) as well as biogeochemistry (inorganic chemistry, biological particle production and degradation, input and output of matter), conceptually, are relatively closely related. The ocean biogeochemical models are either inorganic models (without a representation of the marine biosphere, e.g., Maier-Reimer and Hasselmann, 1987), "particles only models" representing only biological export production (based on phytoplankton production, e.g., Bacastow and Maier-Reimer, 1990; Najjar et al., 1992), or differing numbers of functional groups and zooplankton (NPZD models and models involving further detailing of functional groups, e.g., Six and Maier-Reimer, 1996; Fasham et al., 1990; Aumont et al., 2003; LeQuéré et al., 2005). A few models also include an interactive sediment (Archer and Maier-Reimer, 1994; Heinze et al., 1999; Maier-Reimer et al., 2005; Ridgwell and Hargreaves, 2007; Gehlen et al., 2008). Due to the lack of sufficient knowledge of the "first principles" governing life processes in the ocean, biogeochemical ocean modelling is still in its developmental phase.

The physical ocean models coupled to ocean biogeochemistry models so far have mostly been z-coordinate models, i.e., their water column is discretised vertically with respect to fixed depth intervals. For physical tracer transport in the ocean, it is intriguing to explore alternative vertical coordinates, since different models still differ significantly with respect to reproducing global tracer distributions (Doney et al., 2004; Orr, 2002). The vertical coordinate of isopycnal ocean models mimics the real structure of the water column as stratified layers of constant density and, therefore, avoids a number of problems associated with z-coordinates. Downslope flows play a major role in deep water formation and the ventilation of the abyssal ocean. Isopycnal ocean models are able to maintain the density signal of these downslope flows considerably better than z-coordinate models, especially at the spatial resolutions generally used in climate model ocean components (Winton et al., 1998). The other important issue avoided in isopycnal ocean models is the spurious diffusion that is caused by numerical schemes designed to simulate isopycnal advection and mixing in z-coordinate models (Gnanadesikan, 1999; Griffies et al., 2000). Since the rate at which biological cycling within the ocean occurs is strongly determined by vertical diffusion (Gnanadesikan et al., 2004), limiting this spurious diffusion is potentially critical to get- ting the right rates of chemical cycling. The disadvantages of isopycnal ocean models include the problem of massless layers, the necessity of adding a mixed layer model to adequately represent surface processes, and the introduction of a horizontal pressure gradient error by the sloping density surfaces. Therefore, models with different vertical schemes complement each other and can be used as one basis for an uncertainty assessment of simulations of past, present and future climate.

Here, we present a new coupled isopycnic physicalbiogeochemical model based on two already well-established components: the dynamical isopycnic ocean model MICOM (Bleck and Smith, 1990; Bleck et al., 1992) with a series of modifications (Bentsen et al., 2004) and the biogeochemical model HAMOCC (Maier-Reimer et al., 2005). While MI$\mathrm{COM}$ has been used successfully in abiotic tracer transport studies (Orr, 2002; Gao et al., 2005; Orre et al., 2008) and also for carbon uptake studies (Matsumoto et al., 2004), integrations including nutrients, oxygen and carbon had to be limited to short periods since the computations were too demanding for resources at the time (Drange, 1996).

Initially, we will give a description of the model components and the changes made to HAMOCC to make it compatible with an isopycnic ocean model. After this, we evaluate the circulation and temperature and salinity distributions in the physical model. We evaluate the main biogeochemical model parameters with respect to the physical results and present results from several sensitivity studies. In addition, we will also consider the uptake of anthropogenic $\mathrm{CO}_{2}$ in the model and discuss the conclusions that can be drawn from a stand-alone ocean carbon cycle model with a prognostic slab atmosphere.

\section{Model description}

\subsection{The physical ocean model MICOM}

The numerical methods and thermodynamics of MICOM are documented in Bleck and Smith (1990) and Bleck et al. (1992). Several important aspects deviate from the original model in the version of MICOM used in this study. Since the model version employed here includes several new features that have not been published, we will give a fairly detailed model description and evaluate the model performance on a global scale, with a particular view on the influence of the physical model on biogeochemistry.

We use incremental remapping as an advection algorithm as proposed by Dukowicz and Baumgardner (2000). This multi-dimensional, second order accurate algorithm is expressed in flux form and assures conservation for tracers. It also guarantees monotonicity for tracers for any velocity field that does not violate the Courant-Friedrichs-Levy condition of the method. Neither of these conditions was assured in the original flux-corrected transport (FCT) scheme (Zalesak, 1979), used for layer thickness and MPDATA 
(Smolarkiewicz and Margolin, 1998) used for tracers as implemented in MICOM. While the incremental remapping is computationally rather expensive for one tracer, the cost of adding additional tracers and age tracers is modest which makes it well-suited for use with a ocean carbon cycle module that contains a large number of passive tracers.

The original MICOM uses potential density, $\rho_{r}$, with reference pressure at $0 \mathrm{db}$ as the vertical coordinate. This ensures that the very different flow and mixing characteristics in neutral and dia-neutral directions is well represented near the surface since isopycnals and neutral surfaces are similar near the reference pressure. For pressures that differ substantially from the reference pressure, this does not hold. Potential density, with respect to surface pressure, generally becomes significantly non-neutral in the deep ocean and has large-scale inversions in much of the ocean (e.g., Antarctic Bottom Water has a lower potential density with respect to surface pressure than North Atlantic Deep Water). In this study, we choose a reference pressure of $2000 \mathrm{db}$ as the nonneutrality of the isopycnals in the world ocean is then reduced compared to having the reference pressure at the surface (McDougall and Jackett, 2005). Potential density with a $2000 \mathrm{db}$ reference pressure is monotonically increasing with depth, except in some weakly stratified high-latitude haloclines (McDougall and Jackett, 2005). As the vertical coordinate used by an ocean model must be a monotonic function of depth, potential density with a $2000 \mathrm{db}$ reference pressure is now widely used as the vertical coordinate in isopycnal models.

\subsubsection{Pressure gradient force}

Traditionally, MICOM expresses the pressure gradient force (PGF) as a gradient of the Montgomery potential $M$ on an isopycnic surface,

$\frac{1}{\rho} \nabla_{z} p \approx \nabla_{\rho_{r}} M$,

as such a formulation has favourable numerical properties (Hsu and Arakawa, 1990). This is only accurate if the density can be considered a function of potential density and pressure alone. This is not the case (de Szoeke, 2000) and assuming such a functional form of density causes large PGF errors when the pressure is substantially different from the reference pressure. There have been several attempts to modify the MICOM PGF formulation (1) in order to incorporate the effects of a more accurate representation of density (Sun et al., 1999; Hallberg, 2005). Inspired by the recent work of Rainer Bleck (personal communication, 2006), we have based our formulation on Janjić (1977) where the PGF is expressed as a gradient of the geopotential $\phi$ on a pressure surface

$\frac{1}{\rho} \nabla_{z} p=\nabla_{p} \phi$

The geopotential at a certain pressure $p$ is found by integrating the hydrostatic equation from the invariant geopotential at the bottom, $\phi_{b}$ :

$\phi=\phi_{b}-\int_{p_{b}}^{p} \frac{d p}{\rho}$.

A suitable functional form of the equation-of-state has been chosen, inspired by Jackett et al. (2006), that ensures an accurate representation of density compared to the Feistel (2004) equation-of-state and an analytic expression for the integral in Eq. (3).

\subsubsection{Diapycnal mixing}

The diffusivity of diapycnal turbulent mixing, $v_{d}$, in the model is the sum of a background diffusivity and a Richardson number dependent diffusivity:

$v_{d}=v_{b}+v_{r}$,

$v_{b}=\frac{C}{N}, \quad v_{r}=v_{0} \max \left\{0,1-\left(\frac{R i_{g}}{R i_{0}}\right)^{2}\right\}^{3}$,

$N^{2}=\frac{g}{\rho} \frac{\partial \rho}{\partial z}, \quad R i_{g}=\frac{N^{2}}{(\partial u / \partial z)^{2}+(\partial v / \partial z)^{2}}$,

where $N$ is the Brunt-Väisälä frequency and $R i_{g}$ is the local gradient Richardson number. The parameter determining the background diffusivity is set to $C=1.8 \times 10^{-7} \mathrm{~m}^{2} \mathrm{~s}^{-2}$, while the critical Richardson number is $R i_{0}=1$. The maximum $R i_{g}$ dependent diffusivity $v_{0}$ is set to $500 \times 10^{-4} \mathrm{~m}^{2} \mathrm{~s}^{-1}$ in the $300 \mathrm{~m}$ closest to the ocean floor to parameterize gravity current mixing, and $50 \times 10^{-4} \mathrm{~m}^{2} \mathrm{~s}^{-1}$ elsewhere to parameterize shear instability mixing. The parameterization of background diffusivity is taken from Gargett (1984) and the diffusivity is tuned to give a reasonable poleward heat transport in coupled atmosphere-ocean-sea ice simulations (Otterå et al., 2009) and to optimize the distribution of tracers in tracer release experiments (Orre et al., 2009). The numerical implementation of the diapycnal mixing follows the scheme of McDougall and Jackett (2005) but with additional care in handling the vigorous mixing due to shear instabilities. The original MICOM only used the background diffusivity, and the addition of the $R i_{g}$ dependent diffusivity greatly improves the water mass characteristics downstream of overflow regions. Mean values for the background diffusivity $v_{b}$ are $4 \times 10^{-5} \mathrm{~m}^{2} \mathrm{~s}^{-1}$ between 300 and $500 \mathrm{~m}$ in the tropics and $3 \times 10^{-4} \mathrm{~m}^{2} \mathrm{~s}^{-1}$ near the bottom.

\subsubsection{Lateral turbulent mixing}

Lateral turbulent mixing of momentum and tracers is parameterized by Laplacian diffusion where diffusive velocities (diffusivities divided by the local grid size $\Delta$ ) of momentum and tracers are $1.0 \times 10^{-2} \mathrm{~m} \mathrm{~s}^{-1}$ and $0.35 \times 10^{-2} \mathrm{~m} \mathrm{~s}^{-1}$, respectively. With a grid size of about $130 \mathrm{~km}$ at $60^{\circ} \mathrm{N}$ and $60^{\circ} \mathrm{S}$ this gives actual minimum diffusivities of $1300 \mathrm{~m}^{2} \mathrm{~s}^{-1}$ and $455 \mathrm{~m}^{2} \mathrm{~s}^{-1}$ for momentum and tracers, respectively. 
Layer interfaces are smoothed with biharmonic diffusion with a diffusive velocity (biharmonic diffusivity divided by $\Delta^{3}$ ) of $1.0 \times 10^{-2} \mathrm{~m} \mathrm{~s}^{-1}$ giving a minimum diffusivity of about $2.2 \times 10^{13} \mathrm{~m}^{4} \mathrm{~s}^{-1}$.

\subsubsection{Mixed layer}

The mixed layer depth is found by a turbulent kinetic energy balance of a one-dimensional mixed layer of the type described by Kraus and Turner (1967). In the version of MICOM used here, the formulation by Gaspar (1988) is employed. The TKE balance is affected by wind stress, current sheer and surface buoyancy fluxes. Detrainment from and entrainment into the mixed layer are computed as in Bleck (1992). The penetrating shortwave radiation is absorbed using an exponential decay curve. It is assumed that all water is clear water (Jerlov water type 1). Currently, we do not include the effect of phytoplankton on the absorption of shortwave radiation in the physical model.

\subsubsection{Sea-ice}

The thermodynamic module incorporates freezing and melting of sea-ice and snow covered sea-ice (Drange and Simonsen, 1996) and is based on the thermodynamics of Semtner (1976). The dynamic part of the sea-ice module follows the viscous-plastic rheology of Hibler (1979). The dynamic ice module has been further modified by Harder (1996) to include the description of sea-ice roughness and the age of seaice. A third order weighted essential non-oscillatory scheme (Liu et al., 1994) is used for the advection of sea-ice fraction, thickness and age.

\subsection{The ocean carbon cycle model HAMOCC 5.1}

A detailed description of HAMOCC5.1 is given in MaierReimer et al. (2005). The model is based on the work by Maier-Reimer (1993) and has been used to analyse contemporary ocean carbon fluxes coupled to the physical ocean model MPIOM (Marsland et al., 2003) in Wetzel et al. (2005). Here we only summarise its main features and those that deviate from this description either because they were introduced later or because they are relevant for the inclusion of HAMOCC in an isopycnic ocean model. The values of key parameters are summarised in Table 1.

HAMOCC5.1 model uses the formulation of inorganic carbon chemistry in following Maier-Reimer and Hasselmann (1987). Surface $p \mathrm{CO}_{2}$ is computed as a function of prognostic alkalinity, total DIC, temperature, pressure and salinity. Dissolution of calcium carbonate at depth is a function of the carbonate ion saturation state and a constant dissolution rate. The air-sea gas exchange processes of $\mathrm{CO}_{2}$, oxygen and nitrogen are a function of gas solubility, transfer velocity and the difference between partial pressure tracers in the air and water following Wanninkhof (1992). In sea-ice covered areas the fluxes are scaled down to the ice-free part of the grid cell. The model uses gas tracer solubilities according to Weiss (1970) and Weiss (1974), whereas the gas transfer velocity depends on the Schmidt number and prognostic wind speed at the surface. HAMOCC5.1 contains a simple diffusive slab atmosphere which allows the prognostic computation of atmospheric $\mathrm{CO}_{2}$ levels for a stand-alone ocean set-up of the model forced by atmospheric reanalysis.

The model includes an ecosystem model of the NPZD (Nutrient-Phytoplankton-Zooplankton-Detritus) class (Six and Maier-Reimer, 1996) with nutrient co-limitations by phosphate, nitrate and iron according to

nutrient $=\min \left(\mathrm{PO}_{4}, \frac{\mathrm{NO}_{3}}{R_{\mathrm{N}: \mathrm{P}}}, \frac{\mathrm{Fe}}{R_{\mathrm{Fe}: \mathrm{P}}}\right)$

Nutrient, carbon and oxygen uptake and re-dissolution are treated according to Redfield stoichiometry with the constant proportions of $\mathrm{P}: \mathrm{N}: \mathrm{C}: \mathrm{Fe}$ of $1: R_{\mathrm{N}: \mathrm{P}}: R_{\mathrm{C}: \mathrm{P}}: R_{\mathrm{Fe}: \mathrm{P}}$ (1:16:122:3.7 $\times 10^{-4}$, see Takahashi et al. (1985) for P:N:C). The growth of the single phytoplankton class is described by Michaelis-Menten kinetics and is in addition to nutrients limited by temperature and light intensity following Eppley (1972). Exported organic matter is remineralised throughout the water column below the euphotic zone and the non-remineralised particles are collected by a sediment module. The organic tissue exported as Particulate Organic Carbon (POC) is associated with two major functional phytoplankton groups: diatoms and coccolithophores. Assuming that diatoms are the faster growing group, the amount of opal shells exported with the POC is computed first as a function of silicate concentration as a proportion of the total POC export. The remaining POC export is assumed to contain $\mathrm{CaCO}_{3}$ shells.

In the tropical oligotrophic, nitrate depleted regions, the marine ecosystem module accounts for atmospheric nitrogen fixation essential for cyanobacteria growth. Compared to the model version described in Maier-Reimer et al. (2005), the most recent version of HAMOCC includes sulphate reduction in oxygen-poor waters and sediments in addition to nitrate reduction once all nitrate has been utilized as well. Also, a quadratic zooplankton mortality has been introduced to eliminate spurious Lotka-Volterra cycles that were present in earlier model versions, particularly, in the equatorial Pacific. Remineralisation is now composed of three compartments: remineralisation of particulate organic carbon, dissolved organic carbon as in Maier-Reimer et al. (2005) and now also dying phytoplankton.

Monthly mean dust deposition fields from Mahowald et al. (2005) are used to provide iron input to the ocean. Dissolved iron is released from the dust immediately after deposition in the surface layer assuming a fixed weight percentage of iron (3.5\%) and a constant solubility $\left(1.8 \times 10^{-4} \mathrm{kmol} \mathrm{kg}^{-1}\right)$. The resultant surface iron deposition to the ocean is $5.08 \times 10^{11}$ moles $\mathrm{Fe} \mathrm{yr}^{-1}$. Iron is taken up by marine organisms with a fixed ratio to phosphate $\left(R_{\mathrm{Fe}: \mathrm{P}}\right)$ as described above. Iron scavenging is parameterized 
Table 1. HAMOCC parameters, their symbols and values in the reference experiment.

\begin{tabular}{|c|c|c|}
\hline \multicolumn{3}{|l|}{ Euphotic zone } \\
\hline \multicolumn{3}{|l|}{ Phytoplankton } \\
\hline initial slope of the P-I-curve & $\alpha$ & $0.02 \mathrm{~d}^{-1}\left(\mathrm{~W} \mathrm{~m}^{-2}\right)^{-1}$ \\
\hline maximum growth rate & $V_{P}$ & $0.4 \mathrm{~d}^{-1}$ \\
\hline light attenuation coeff. of water & $k_{w}$ & $0.04 \mathrm{~m}^{-1}$ \\
\hline light attenuation coeff. of chlorophyll & $k_{c}$ & $0.006 \times 10^{-6} \times 122 \mathrm{~m}^{-1}\left(\mathrm{kmol} \mathrm{P} \mathrm{m}^{-3}\right)^{-1}$ \\
\hline half-saturation constant for $\mathrm{PO}_{4}$ & $R_{\mathrm{PHY}}^{\mathrm{PO}_{4}}$ & $10^{-7} \mathrm{kmol} \mathrm{P} \mathrm{m}^{-3}$ \\
\hline half-saturation constant for $\mathrm{Si}(\mathrm{OH})_{4}$ & $R_{\mathrm{PHY}}^{\mathrm{Si}(\mathrm{OH}) 4}$ & $10^{-6} \mathrm{kmol} \mathrm{P} \mathrm{m}^{-3}$ \\
\hline Fe:P uptake ratio & $R_{\mathrm{Fe}: \mathrm{P}}$ & $3 \times 10^{-6} \times 122 \mathrm{~mol} \mathrm{Fe} \mathrm{mol} \mathrm{P}{ }^{-1}$ \\
\hline Opal:P uptake ratio & $R_{\mathrm{Si}: \mathrm{P}}$ & $25 \mathrm{~mol} \mathrm{Si} \mathrm{mol} \mathrm{P} \mathrm{P}^{-1}$ \\
\hline $\mathrm{CaCO}_{3}$ uptake ratio & $R_{\mathrm{CaCO} 3: \mathrm{P}}$ & $35 \mathrm{~mol} \mathrm{C} \mathrm{mol} \mathrm{P}-1$ \\
\hline remineralisation rate & $\lambda \stackrel{\text { DOMrf }}{\text { surf }} \mathrm{PO}_{4}$ & $0.03 \mathrm{~d}^{-1}$ \\
\hline mortality rate & $\lambda_{\mathrm{PHY}, \mathrm{DET}}^{\text {surf }}$ & $0.008 \mathrm{~d}^{-1}$ \\
\hline exudation rate & $\lambda_{\mathrm{PHY}, \mathrm{DOM}}$ & $0.03 \mathrm{~d}^{-1}$ \\
\hline \multicolumn{3}{|l|}{ Zooplankton } \\
\hline max grazing rate & $\mu_{\mathrm{ZOO}}$ & $1 \mathrm{~d}^{-1}$ \\
\hline half-saturation constant for grazing & $K_{\mathrm{ZOO}}$ & $4 \times 10^{-8} \mathrm{kmol} \mathrm{P} \mathrm{m}^{-3}$ \\
\hline mortality rate & $\lambda_{\mathrm{ZOO}}^{\text {surf }}$ & $5 \times 10^{6} \mathrm{~d}^{-1}$ \\
\hline excretion rate & $\lambda \mathrm{ZOO}, \mathrm{DOM}$ & $0.03 \mathrm{~d}^{-1}$ \\
\hline \multicolumn{3}{|l|}{ Deep Ocean } \\
\hline Detritus remineralisation rate & $\lambda_{\mathrm{DET}, \mathrm{PO} 4}^{\text {deep }}$ & $0.003 \mathrm{~d}^{-1}$ \\
\hline DOC remineralisation rate & $\lambda_{\mathrm{DOM}, \mathrm{PO} 4}^{\text {deep }}$ & $0.004 \mathrm{~d}^{-1}$ \\
\hline Opal dissolution rate & $\lambda_{\mathrm{OPAL}, \mathrm{Si}(\mathrm{OH}) 4}$ & $0.005 \mathrm{~d}^{-1}$ \\
\hline $\mathrm{CaCO}_{3}$ dissolution rate & $\lambda_{\mathrm{CaCO} 3, \mathrm{DIC}}$ & $0.075 \mathrm{~d}^{-1}$ \\
\hline Phytoplankton mortality rate & $\lambda_{\mathrm{PHY}, \mathrm{DET}}^{\text {deep }}$ & $0.1 \mathrm{~d}^{-1}$ \\
\hline Zooplankton mortality rate & $\lambda_{\text {ZOO,DET }}^{\text {deep }}$ & $0.2 \mathrm{~d}^{-1}$ \\
\hline Detritus sinking speed & $w_{\mathrm{POC}}$ & $5 \mathrm{~m} \mathrm{~d}^{-1}$ \\
\hline Opal sinking speed & $w_{\mathrm{Si}(\mathrm{OH}) 4}$ & $80 \mathrm{~m} \mathrm{~d}^{-1}$ \\
\hline $\mathrm{CaCO}_{3}$ sinking speed & $w_{\mathrm{CaCO} 3}$ & $30 \mathrm{~m} \mathrm{~d}^{-1}$ \\
\hline
\end{tabular}

in analogy to Johnson et al. (1997). This approach assumes that dissolved iron beyond the limit of $0.6 \mathrm{nmoll}^{-1}$ is complexed by strong iron binding ligands with a time constant. This iron is lost to the biogeochemical cycle. Iron is not included in the sediment module and, thus, there is no iron re-dissolution from the sediment.

HAMOCC5.1 only allows biological production in the top $90 \mathrm{~m}$ of the water column. In a $\mathrm{z}$-level model, this simply implies computing biological production in the layers that lie above this depth. In an isopycnic model, layer thickness changes over time and space. Thus, we redefined the origi- nal criterion and now test for changes in layer thickness at every time step of the biogeochemical model: in order for biological production to occur at least $10 \mathrm{~m}$ of an isopycnic layer must lie within the $90 \mathrm{~m}$ euphotic zone. The layer that contains the $90 \mathrm{~m}$ boundary is split virtually into a part above and one below the euphotic zone boundary and is assumed to be instantly well-mixed (Fig. 1). Changes in nutrient concentrations etc. due to biological production are calculated with respect to the concentration in the entire layer and then scaled proportionally to the thickness of the layer that lies in 
surface

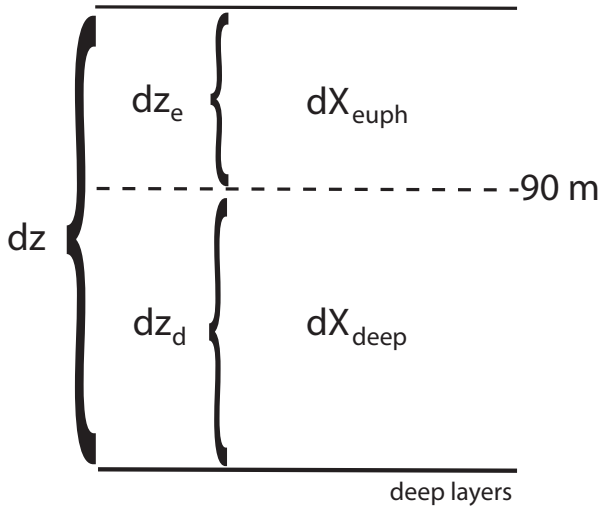

Fig. 1. Schematic diagram illustrating the virtual split of the model layer containing the $90 \mathrm{~m}$ deep lower boundary of the euphotic zone. Please note that this $90 \mathrm{~m}$ boundary may lie either within the mixed layer or below the mixed layer and a number of thin or massless layers, not necessarily in the second layer below the surface.

the euphotic zone.

$X_{\text {new }}=\frac{X_{\text {old }} \times d z_{\mathrm{d}}+\left(X_{\text {old }}+d X_{\text {euph }}\right) \times d z_{\mathrm{e}}}{d z}$

where $X$ is any biogeochemical tracer, $d X_{\text {euph }}$ the change in $X$ due to biological production, $d z$ is the total layer thickness and $d z_{\mathrm{e}}$ and $d z_{\mathrm{d}}$ the parts of the layer that lie in the euphotic zone and below it, respectively. The diagnosed values for primary and export production follow the formulation for biological production and are also scaled to the top $90 \mathrm{~m}$. Similarly, the part of the same layer that lies below the euphotic zone boundary experiences the remineralization processes that occur in the deep ocean resulting in $d X_{\text {deep }}$.

$X_{\text {new }}=\frac{X_{\text {old }} \times d z_{\mathrm{e}}+\left(X_{\text {old }}+d X_{\text {deep }}\right) \times d z_{\mathrm{d}}}{d z}$

We used HAMOCC's implicit sinking scheme with fixed sinking velocities, but excluded massless layers from the routine. The 12-layer sediment model included in HAMOCC5.1 was used without amendment. It exchanges fluxes with the lowest ocean layer exceeding $0.5 \mathrm{~m}$ in thickness. Export production in HAMOCC is calculated at the $90 \mathrm{~m}$ euphotic zone boundary and only includes the sinking POC, but not DOM advection.

HAMOCC's biogeochemical tracers are advected and mixed as passive tracers in MICOM. MICOM uses a leapfrog time stepping scheme. The biogeochemical tracers are only defined on one of the two time levels of the time stepping scheme. This increases computational efficiency since the inclusion of a large number of passive tracers significantly increases computation time especially in MICOM's advection and mixing routines. Therefore, we corrected the global tracer budget for changes in layer thickness caused by time-smoothing between the two physical time levels to ensure tracer conservation.

\subsection{Model configuration, initialisation and forcing}

The model is configured on a global grid where the Northern Hemisphere grid singularity was moved to a position over central Siberia to avoid a singularity in the computational ocean domain (Furevik et al., 2003, Fig. 1b). At the equator, the grid resolution is $2.4^{\circ}$ zonally and $0.8^{\circ}$ meridionally. With increasing latitude the grid cells are gradually transformed to have more isotropic metric scale factors in the horizontal directions. The grid spacing ranges from $60 \mathrm{~km}$ in the Arctic and Southern Oceans to $180 \mathrm{~km}$ in the subtropical gyres. In the vertical, the model has 35 layers of which the uppermost is a mixed layer with temporally and spatially varying density. The potential densities of the isopycnal layers are in the range of $1030.12-1037.80 \mathrm{~kg} \mathrm{~m}^{-3}$.

The physical model is initialised from the rest with temperature and salinity distributions based on the January climatologies from Levitus and Boyer (1994) and Levitus et al. (1994), respectively. Nutrients and DIC/Alkalinity in HAMOCC were initalised from global mean vertical profiles based on WOA05 (Boyer et al., 2006) and GLODAP (Sabine et al., 2005), respectively. The model was spun up for 950 years. The first 600 of these were performed with a monthly NCEP-based climatology (Kalnay et al., 1996). This does not include the synoptic and interannual variability necessary to obtain realistic sea-ice distributions and surface mixing and mixed layers, and we switched to repeated passes of the NCEP Reanalysis 1950-1999 for another 350 years of spin-up. We terminated the spin-up when successive passes of NCEP Reanalysis yielded virtually identical global $\mathrm{CO}_{2}$ fluxes. For the last 2 passes of NCEP Reanalysis 1950-99, the rms difference between the air-sea $\mathrm{CO}_{2}$ fluxes, which vary between $-0.3 \mathrm{Pg} \mathrm{Cyr}^{-1}$ and $0.3 \mathrm{PgC} \mathrm{yr}^{-1}$, is $0.0245 \mathrm{GtC} \mathrm{yr}^{-1}$. This implies that the airsea $\mathrm{CO}_{2}$ fluxes are basically reproduced between the two runs. Volume-weighted rms differences for the mean 1990 1999 distributions of phosphate, oxygen and DIC are $0.8 \%$, $0.9 \%$ and $0.06 \%$, respectively. Since spatial DIC variations are approximately $10 \%$ of the global mean, the real DIC error probably corresponds more to something like $0.6 \%$.

The NCEP Reanalyses provide radiative fluxes and turbulent surface fluxes of momentum and heat, along with information on the ocean surface state (temperature and seaice concentration). The forcing scheme and procedure, proposed in Bentsen and Drange (2000), is used here. The scheme reproduces the NCEP Reanalyses fluxes if the model has the same surface state as in the reanalysis. These states will generally differ, however, and the fluxes are modified 
accordingly. The turbulent fluxes are modified consistent with the bulk parameterization of Fairall et al. (1996) and long-wave radiative fluxes consistent with the Berliand and Berliand (1952) parameterization. Precipitation is directly provided by the NCEP Reanalyses and the evaporation is calculated based on the (modified) latent heat flux. To maintain a stable and realistic Atlantic meridional overturning circulation (AMOC) during the spin-up and years before 1948, a Newtonian relaxation of sea-surface salinity (SSS) and seasurface temperature (SST) is applied with a relaxation time scale of 30 days for a $50 \mathrm{~m}$ thick mixed layer, linearly decreasing with thicker mixed layers (see Bentsen et al., 1999). For the experiments, forced by NCEP Reanalyses after 1948, this is reduced to 60 days for SSS and 180 days for SST to allow the development of surface SST and SSS anomalies, while still maintaining a realistic AMOC.

The model is initialised with a preindustrial atmospheric $\mathrm{CO}_{2}$ level of $278 \mathrm{ppm}$ and is then allowed to evolve freely during the spin-up. It stabilises at a value of $286 \mathrm{ppm}$. We start our emission scenario, run in 1860 , using values for anthropogenic $\mathrm{CO}_{2}$ emissions from Boden et al. (2009). Since no gridded physical atmospheric forcing data exists prior to 1948, we use perpetual forcing with the NCEP year 1959 for the period 1860-1947. 1959 is both relatively neutral for both NAO (see e.g. http://www.cru.uea.ac.uk/cru/ climon/data/nao/) and ENSO (see e.g. http://www.cdc.noaa. gov/people/klaus.wolter/MEI/), as well as being early in the NCEP period. This should ensure that air temperatures and Southern Ocean winds are still relatively close to preindustrial conditions. Prior to starting the emission simulations, the model was run with year 1959 forcing but no emissions for 20 years to avoid a drastic change at the start of the emission simulation. Initially, four simulations were performed:

- CLIM: the reference simulation that continues the spinup. Forced by NCEP year 1959 without $\mathrm{CO}_{2}$ emissions for the entire 1860-2007 period.

- CLIM + EMS: forced by NCEP year 1959 for the entire 1860-2007 period, but with anthropogenic $\mathrm{CO}_{2}$ emissions from 1860 to 2007.

- SYN: forced by NCEP Reanalyses 1948-2007 without $\mathrm{CO}_{2}$ emissions. Initialised from CLIM at the end of year 1947.

- SYN + EMS: forced by NCEP Reanalyses 1948-2007 and including anthropogenic $\mathrm{CO}_{2}$ emissions for this period. Initialised from CLIM + EMS at the end of 1947.

\section{Model results and evaluation}

Since most available observational data were obtained over the last three decades, we use an average of the years 19782007 of the SYN + EMS simulation for comparison to global
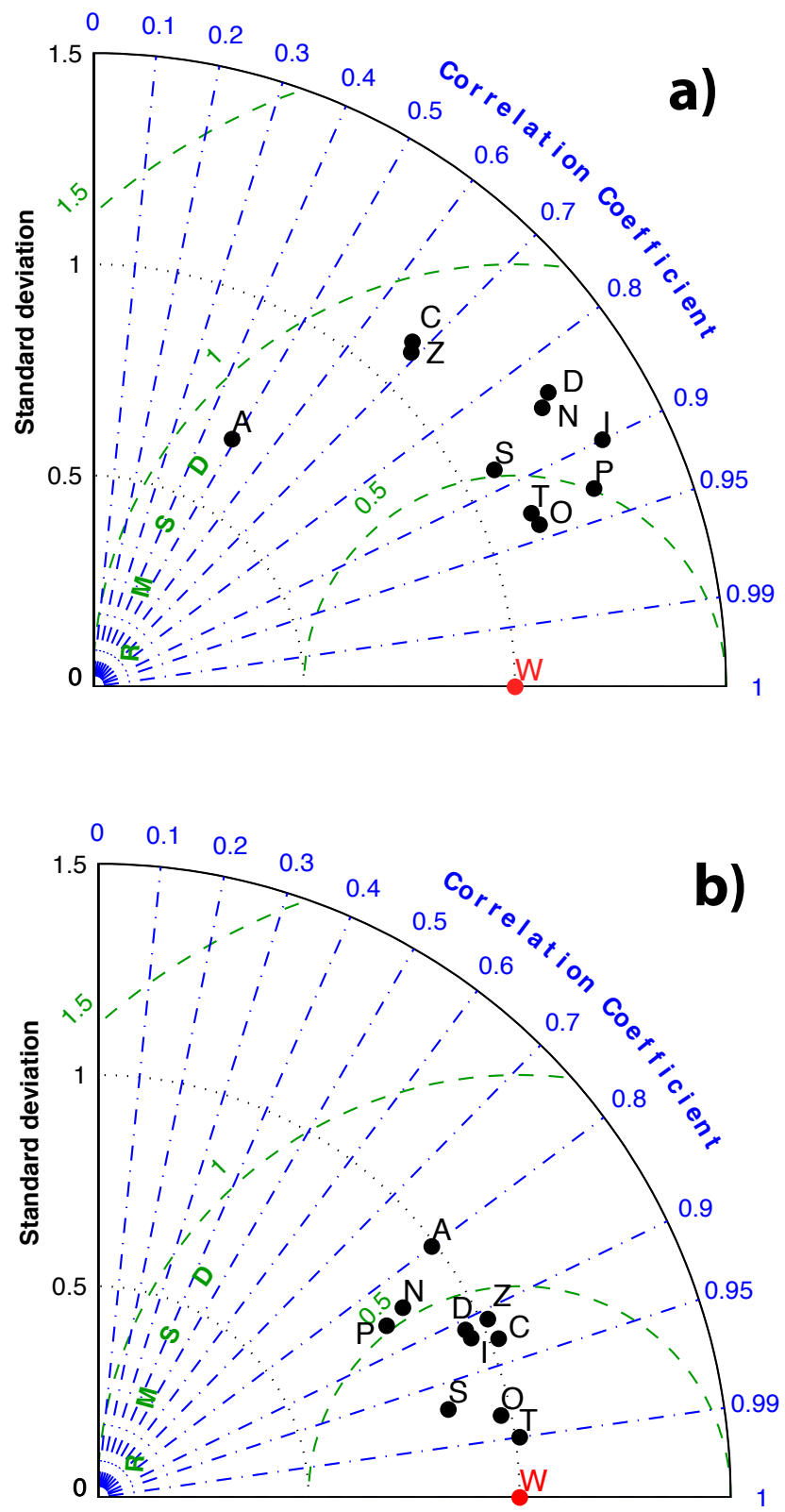

Fig. 2. Taylor diagram (Taylor, 2001) comparing simulated mean (1978-2007) and observed fields (a) for the entire ocean weighted by volume, (b) for the surface weighted by area. $T$ - potential temperature, $S$ - salinity, $\mathrm{P}$ - phosphate, $\mathrm{N}$ - nitrate, I - silicate, $\mathrm{O}$ oxygen, D - DIC, A - Alkalinity, C - CFC11, Z - CFC12, the red $\mathrm{W}$ and dot denote the observations. Climatologies for temperature, salinity, phosphate, nitrate, silicate and oxygen are from WOA05 (Boyer et al., 2006), those for DIC, Alkalinity, CFC11 and CFC12 from GLODAP (Sabine et al., 2005). Standard deviations were normalised to combine the different variables in one diagram. The Taylor diagram provides a concise statistical summary of how well the simulated tracer distributions match the observed ones in terms of their correlation (the azimuthal position on the diagram), their relative standard deviations (the radial distance), and their root-meansquare difference (the green dashed circles). The observations are placed at the point on the diagram where both correlation and standard deviation are 1 . 

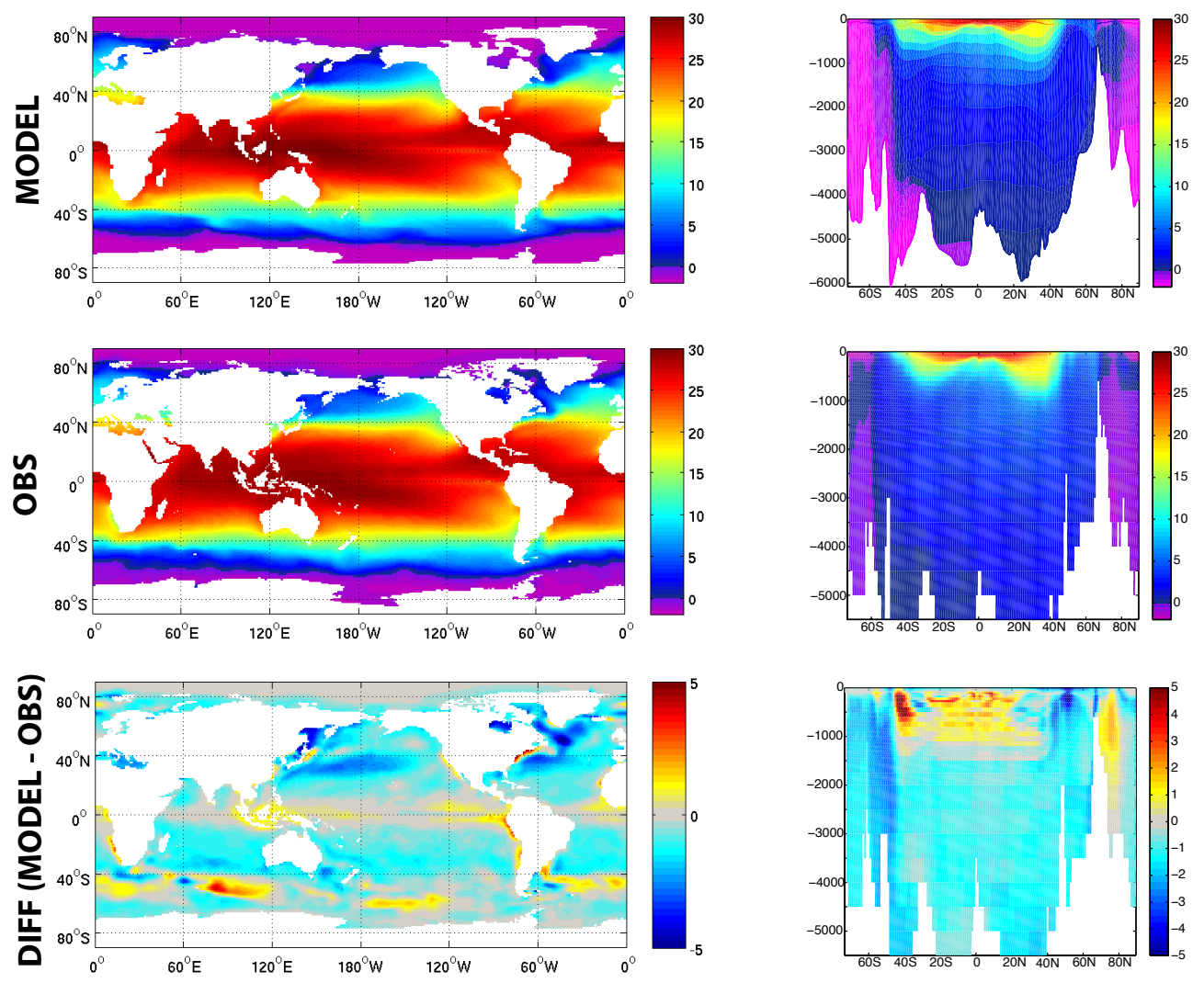

Fig. 3. Surface distributions (left) and meridional sections through the western Atlantic (right) of simulated (top), and observed (middle) potential temperature $\left({ }^{\circ} \mathrm{C}\right)$ and their difference (bottom). Model results are a mean 1978-2007 and observations from the same sources as in Fig. 2. Model results were interpolated onto the same $1^{\circ} \times 1^{\circ}$ grid as the observations for the comparison.

climatologies. We summarise model performance in a Taylor diagram (Fig. 2), and provide a more detailed discussion in the following sections. 3-D fields of model variables generally display correlations exceeding 0.8 with their observed equivalents. Correlations for potential temperature, salinity and phosphate are higher than those shown in Schneider et al. (2008) which is partly due to the fact that we use a forced ocean model instead of the fully coupled climate carbon cycle models compared in Schneider et al. (2008). It is interesting to note, however, that our model generally has higher standard deviations for the 3-D fields than the observations, while all models compared in Schneider et al. (2008) underestimate these. Surface distributions of physical and biogeochemical tracers in our model show higher correlations to observations than the full 3-D fields. Their standard deviations are markedly closer to those observed and in some cases lie below them. This indicates that our model simulation mainly overestimates gradients in the deep ocean, this is likely due to the fact that isopycnal models are much less diffusive that their z-level counterparts.

\subsection{Physical model}

Amended versions of MICOM have been evaluated in several studies throughout its development, particularly in the North Atlantic (e.g. Nilsen et al., 2003; Bentsen et al., 2004; Gao et al., 2005; Drange et al., 2005; Hatun et al., 2005; Lohmann et al., 2009). Here, we present an evaluation of the main features of the physical model mainly to provide a context for the biogeochemical tracer distributions.

Overall, the simulated circulation as well as the potential temperature and salinity fields are realistically described by the model. The model reproduces both global salinity $S$ and potential temperature $\Theta$ distributions well, with a slighty better pattern representation for temperature (Fig. 2). Simulated distributions have larger normalised standard deviations (STD), i.e. stronger gradients, than observed. This is likely due to MICOM not being very diffusive and to low exchange between the isopycnal layers and their outcropping region in the surface mixed layer across their diapycnal interface. Surface distributions for both salinity and temperature are close to the observed ones (Figs. 3 and 4). Since salinity is relaxed quite strongly to observations, SSS deviations are generally below $0.2 \mathrm{psu}$. Notable exceptions are 

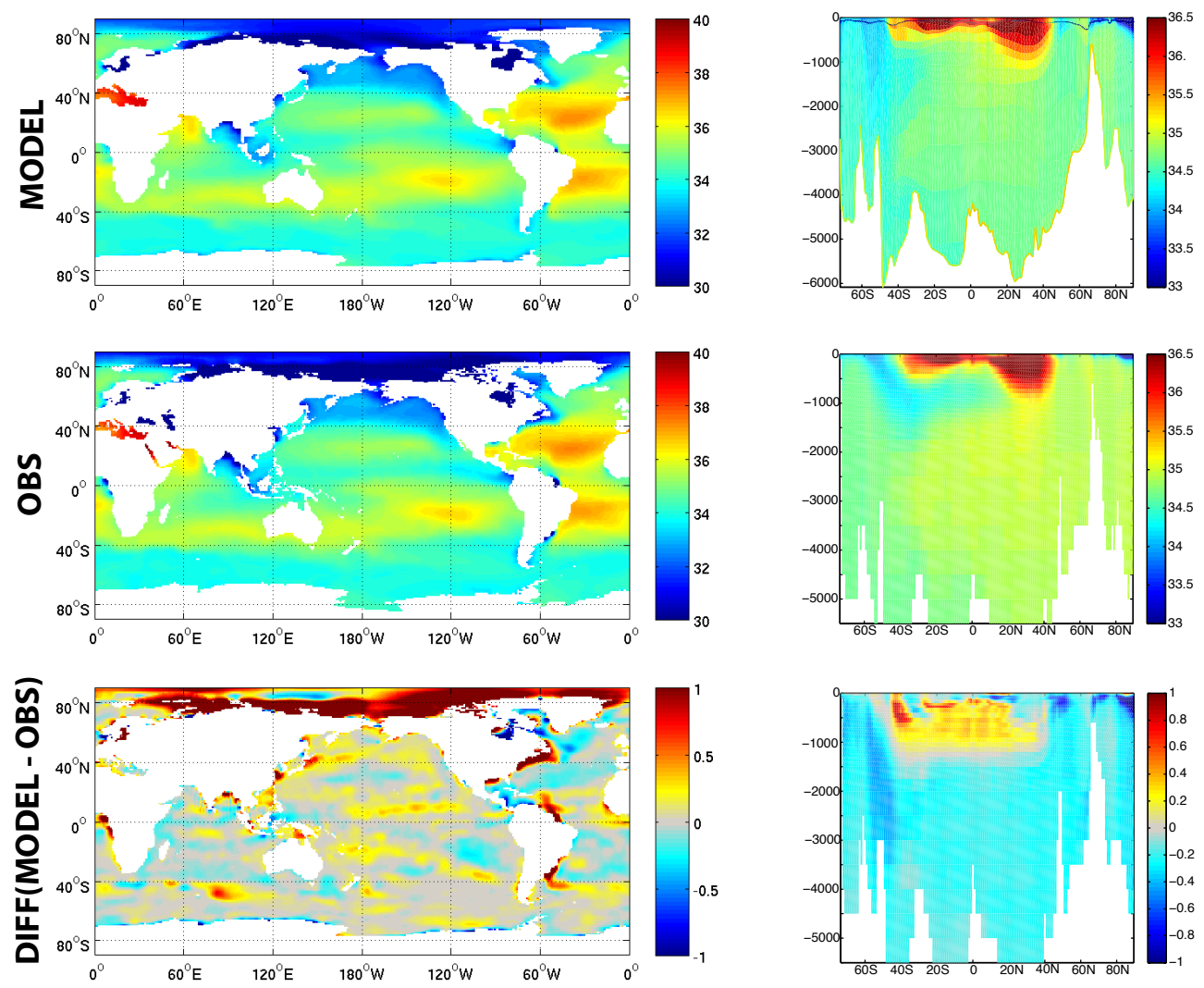

Fig. 4. As Fig. 3, but for salinity (psu).

the estuaries/plumes of big rivers, especially in the Arctic, in whose vicinity the model overestimates salinity. Rather than explicitly prescribing river fresh water fluxes, MICOM uses a run-off scheme to route NCEP precipitation on land into the ocean. While this ensures fresh water conservation, it means that fresh water inputs from continents in the model do not completely agree with the real ones, especially in the vicinity of big rivers. Deviations in both SSS and SST in the North Atlantic can be explained by deviations in the path of the North Atlantic Current that leaves the North American coast too far North as is common in coarse resolution models. The resulting large heat loss may lead to low SSTs in the sub-polar gyre and northwestern sub-tropical gyre. The North Pacific and Kuroshio show a similar pattern. SSTs are generally too cold. A notable exception are the upwelling regions where overestimated temperatures indicate that the upwelling strength is too weak.

Meridional sections in the Atlantic show that the model produces deep and bottom water masses that are too fresh and cold (Figs. 3 and 4). Simulated sub-surface and deep waters in the Greenland Sea are warmer and slightly fresher than observed, possibly due to underestimated convection intensity in the model. The overly cold and fresh waters in the Labrador Sea in our simulation stem from two origins: A Denmark Strait overflow where water appears to experience too little entrainment during its descent and local convection of overly fresh and cold surface waters in the Labrador Sea caused by misrepresentations in the course of the North Atlantic Current.

Overestimated $\Theta$ and $S$ above $1000 \mathrm{~m}$ in the tropics and subtropics indicate weak replenishment of Sub-antarctic Mode Water (SAMW) and Antarctic Intermediate Water (AAIW). Water with the characteristically low salinity of AAIW is subducted to depths of up to $3000 \mathrm{~m}$ in the AAIW formation regions, because its temperatures are too low by $2.5^{\circ} \mathrm{C}$ and, thus, its density allows it to sink to these depths. The source of this cold water can be found further South. While deep convection and formation of cold and saline waters is only observed on Antarctic shelves, the water column of the deep Weddell Sea is only weakly stratified when using the surface as a reference level for potential density. In fact, the choice of $2000 \mathrm{~m}$ as a reference level for our model density layers means that the observed stratification in this area is unstable (Fig. 5). This initially leads to overestimated vertical mixing in our model which erodes the Warm Deep Water core in the Weddell Sea, an area whose representation in ocean models is particularly sensitive to the parametrisation of vertical mixing (Timmermann and Beckmann, 2004). Due to the long spin-up of the model, this leads to a relatively homogeneous cold water column throughout the Southern Ocean, and both Antarctic Bottom Water $(\mathrm{AABW})$ and Central Intermediate Water (CIW) exported 


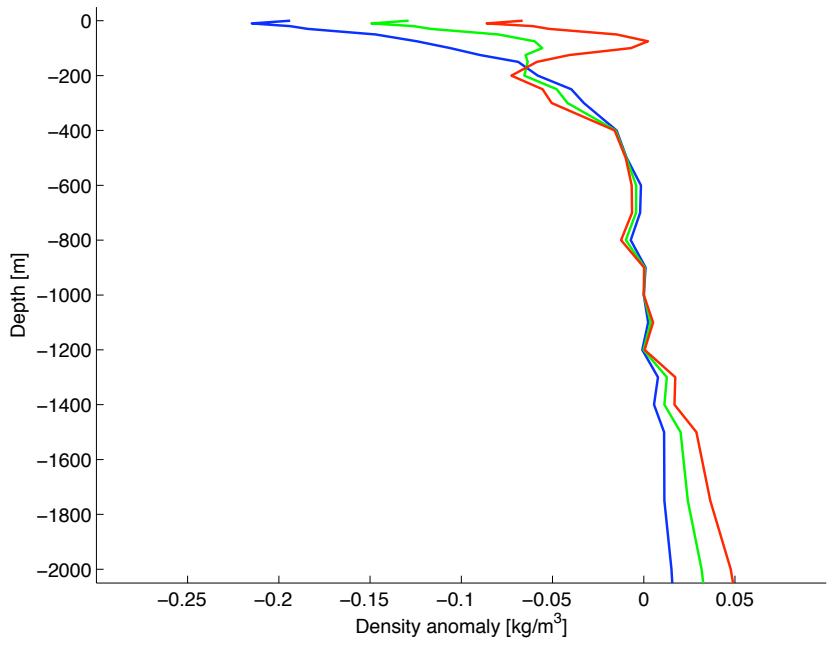

Fig. 5. Potential density profiles with reference pressure of $0 \mathrm{db}$ (blue line), $1000 \mathrm{db}$ (green line), and $2000 \mathrm{db}$ (red line) in the Weddell Sea $\left(70^{\circ} \mathrm{S}-60^{\circ} \mathrm{S}, 40^{\circ} \mathrm{W}-0^{\circ} \mathrm{W}\right)$. The profiles are computed using August data from Levitus and Boyer (1994) and Levitus et al. (1994) and the density anomaly is relative to density at $1000 \mathrm{~m}$.

are colder than observed. Consequently, water upwelled in the southern limb of the Deacon Cell (Fig. 6a) is too cold and leads to the excessive subduction of AAIW described above. Erosion of the warm CDW core due to excessive vertical mixing also leads to an overestimated sea-ice cover in the Southern Ocean.

This process also leads to the relatively strong AABW cell of $14 \mathrm{~Sv}$ in the global meridional overturning circulation (Fig. 6a) since the deep AABW outflow is joined by water which would normally exit the Southern Ocean as AAIW at much shallower depths. Observations (Orsi et al., 1999) indicate that $8-9.5 \mathrm{~Sv}$ of AABW are exported northwards. The model shows a North Atlantic overturning of $14 \mathrm{~Sv}$ which lies at the upper end of values found in the CORE simulations (Griffies et al., 2009). Lumpkin et al. (2008) use hydrographic sections and an inverse box model to determine the overturning strength at $48^{\circ} \mathrm{N}$. They deduce a value of $16-18 \mathrm{~Sv}$ which lead us to believe that our simulated value is realistic within the uncertainties. Major features of the horizontal circulation (Fig. 6b) are in general well-reproduced with an ACC strength of 150-160 Sv, a Weddell Gyre of $50 \mathrm{~Sv}$ (Beckmann et al., 1999), a Ross Gyre of 20-30 Sv (Assmann and Timmermann, 2005) and a North Atlantic Sub-tropical and Sub-polar Gyres of 30-40 Sv.

Mixed Layer Depth (MLD) has a critical influence on biological production, since it determines light and nutrient availability. Simulated MLDs (Fig. 7) agree fairly well with those derived from observations (e.g. Schneider et al., 2008). Our model does not produce the excessively deep mixed layers especially in the Southern Ocean that isopycnic models have struggled with in the past. Southern Ocean MLDs in our model are if at all slightly underestimated. Improved convec- tion and entrainment schemes as well as the artificially stable Southern Ocean water column resulting from the erosion of the Circumpolar Deep Water core may play a role here.

CFCs are a useful tracer to assess the location and strength of ocean ventilation in ocean models and the transport of tracers into the deep ocean. A simulation of CFCs following the Ocean Carbon Cycle Model Intercomparison Project (OCMIP) protocol (http://www.ipsl.jussieu.fr/OCMIP/) confirms many of the points discussed above. Zonally-averaged CFC column inventories agree well with observations in the Northern Hemisphere and tropics (Fig. 8), while Southern Ocean inventories are overestimated due to the high vertical mixing. A section through the western Atlantic shows that modelled CFC11 is higher than observed in both the North Atlantic and Southern Ocean (Fig. 9). This indicates that deep and bottom water formation by deep convection and their replenishment through overflows, as in the North Atlantic, are overestimated in our model.

\subsection{Biogeochemistry}

Correlations for the biogeochemical 3-D fields that we compared generally lie above 0.8 (Fig. 2). As for $\Theta$ and S simulated standard deviations are higher than observed by 10$35 \%$ again indicating that the model overestimates gradients in the distributions.

Phosphate is useful for a baseline assessment of the biogeochemical tracers since it is not affected by air-sea gas exchange. Its surface concentrations are generally low due to uptake during biological production. Higher deep ocean concentrations arise from the remineralisation of this biological matter after sinking out of the euphotic zone. Areas of higher surface phosphate are associated with upwelling, e.g., the Southern Ocean and the equatorial Pacific, or enhanced mixing, e.g. the North Pacific. Lower deep concentrations indicate areas of deep water formation like the North Atlantic.

Simulated surface phosphate concentrations are generally underestimated (Fig. 10). Exceptions are the Siberian shelves, where dissolution from the sediment increases concentrations, and the Southern Ocean below $60^{\circ} \mathrm{S}$. The weak upwelling in the model discussed in the previous section leads to low phosphate concentrations in the equatorial $\mathrm{Pa}-$ cific. Sarmiento et al. (2004) argue that strong vertical tidal mixing is an important process for resupplying the surface waters in the North Pacific. This process is not included in our model and likely contributes to low phosphate concentrations in the model. The North Pacific and the Southern Ocean between $40^{\circ}$ and $60^{\circ}$ are the formation regions for intermediate waters that supply much of the low-latitude ocean with nutrients (Sarmiento et al., 2004). In our simulation, surface phosphate concentrations in these regions are too low and the most obvious deviation from observations. Meridional sections in the Atlantic (Fig. 10) illustrate how the low simulated preformed surface concentrations are communicated into the intermediate water masses. Analysis of the physical 
a)

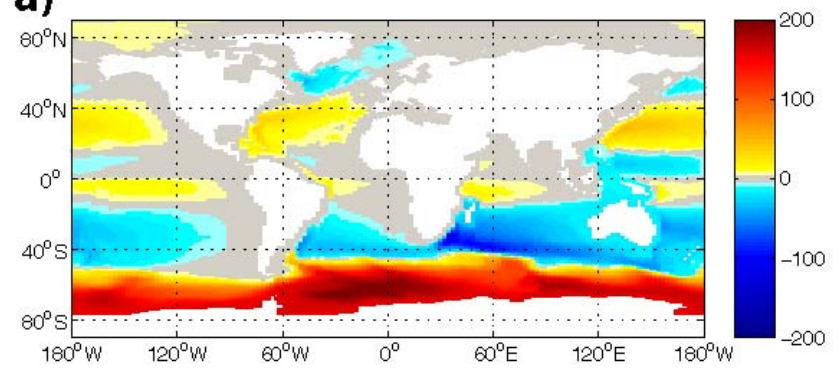

b)

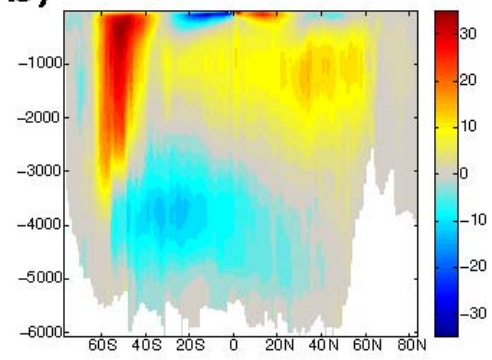

Fig. 6. Simulated mean (1978-2007) global circulation pattern. (a) Barotropic stream function in $\mathrm{Sv}\left(10^{6} \mathrm{~m}^{3} \mathrm{~s}^{-1}\right)$. (b) Global meridional overturning circulation in Sv.
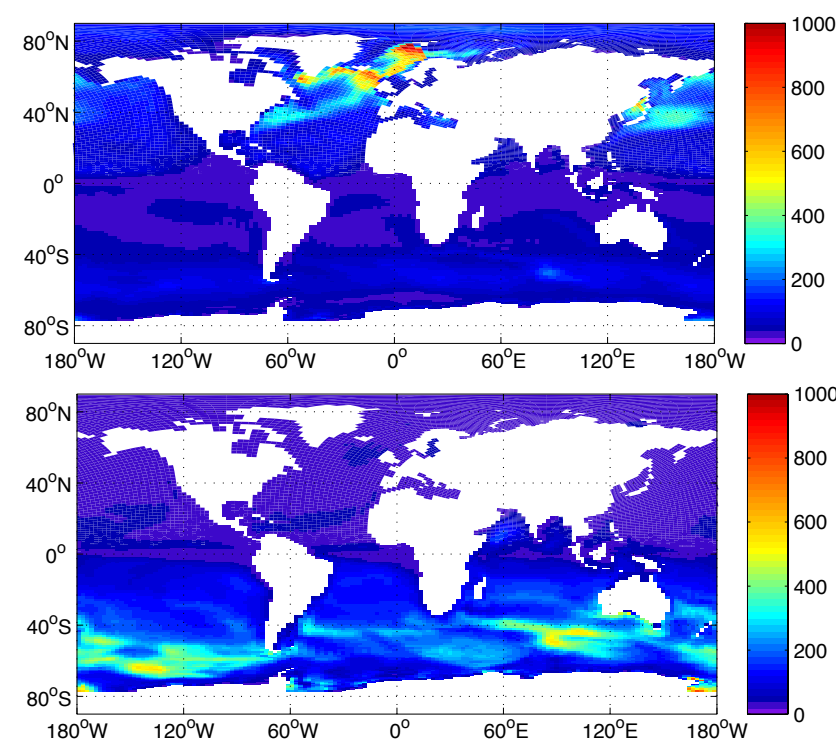

Fig. 7. Simulated mean (1978-2007) March (top) and August (bottom) mixed layer depths in $\mathrm{m}$.

fields showed that the model's Antarctic Intermediate Water (AAIW) tongues are less pronounced than in observations. The subduction of low-salinity water that would normally contribute to AAIW to a much greater depth aids the trapping of nutrients in the Antarctic Marginal Seas and Antarctic Bottom Water (AABW) where the model overestimates nutrient concentrations. We will explore the relative roles of physics and biology for the preformed concentrations in the AAIW formation regions through sensitivity studies in Sect. 5 .

To first order, the global distribution of oxygen is a mirror image of the distribution of nutrients. In addition, surface oxygen concentrations bear the imprint of temperature dependent dissolution with higher concentrations in cold highlatitude waters. The close link to temperature is reflected by very similar performance of oxygen and temperature in the Taylor diagram (Fig. 2). A comparison of modelled and observed surface oxygen distributions (Fig. 11) shows that deviations are small except in the Arctic and Southern Oceans.

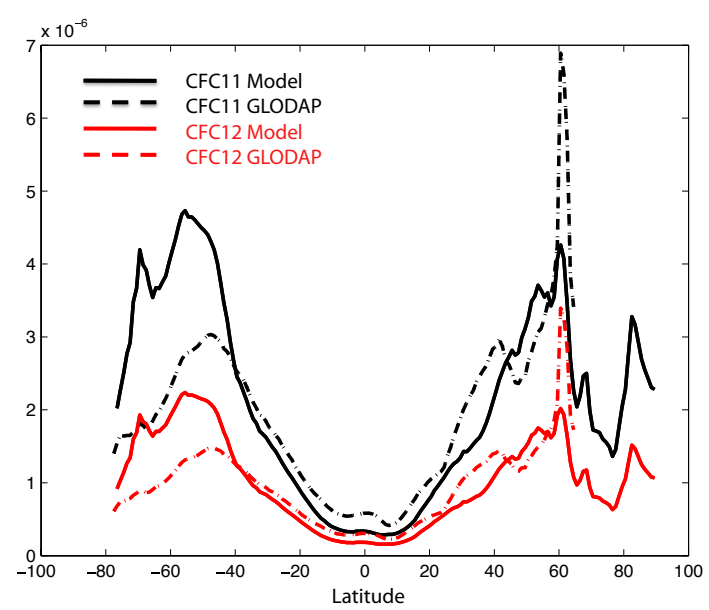

Fig. 8. Zonal mean inventories of CFC11 (black) and CFC12 (red) in $\mathrm{mol} \mathrm{m}^{-2}$.

The modelled sea-ice extent in the Southern Ocean is too large in summer and, thus, prohibits air-sea gas exchange. In addition, observations are generally summer-biased in polar regions. This may lead to higher observed oxygen concentrations since they are dominated by oxygen release during biological production. Oxygen content of the deep and bottom water is too high, indicating that vertical mixing in deep water formation regions is overestimated by the model (Fig. 11), but also reflects the underestimated temperatures (Fig. 3). The simulated sub-equatorial oxygen minima are not as pronounced in the model. Reasons for this lie in underestimated upwelling and nutrient supply which lead to low biological production and remineralisation of sinking organic matter. However, it also indicates that our model is not as prone to the nutrient trapping at the Equator commonly seen in biogeochemical ocean models (Aumont et al., 1999). Low AAIW oxygen concentrations confirm the weak formation rates of this water mass in the model.

Dissolved Inorganic Carbon (DIC, Fig. 12) shows, in principle, the same deviations from the observations as phosphate, but performs worse in the Taylor diagram since it is 

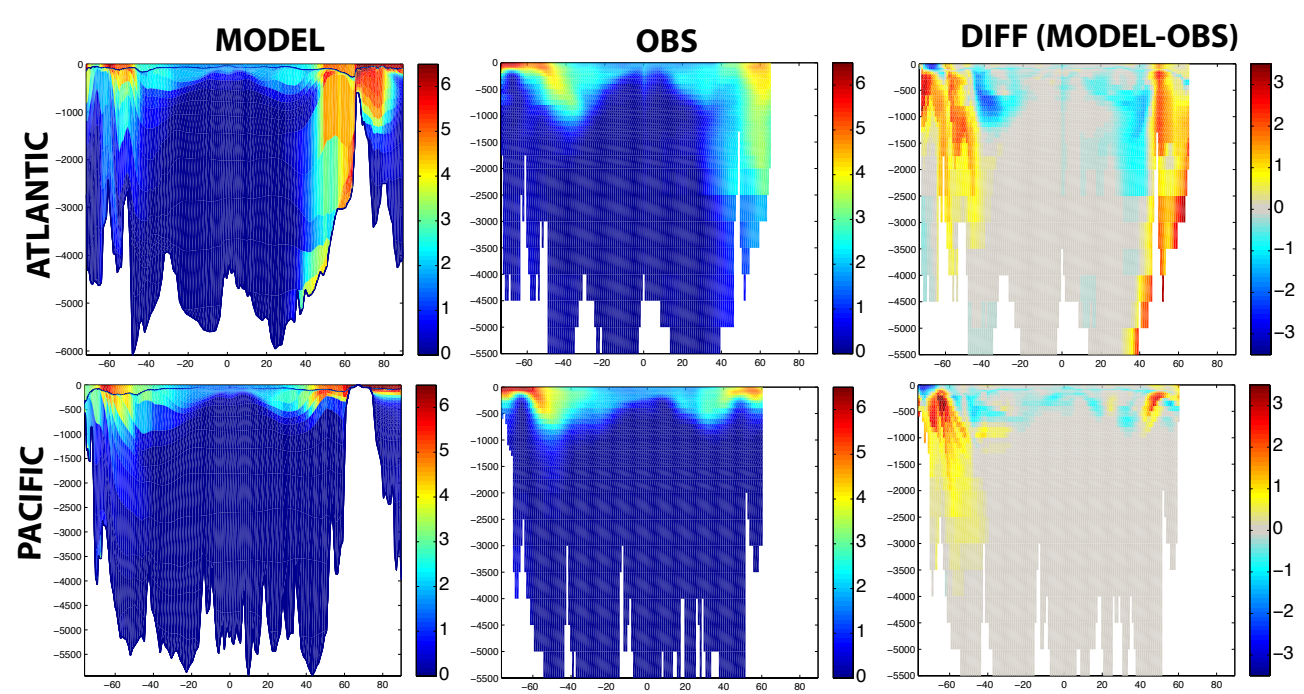

Fig. 9. Meridional sections through the western Atlantic (top) and Pacific of simulated (bottom) of simulated (left) and observed (middle) CFC11(nmol $1^{-1}$ ) and their difference (right). Model results are a mean 1988-1997 and observations from GLODAP (Sabine et al., 2005). Model results were interpolated onto the same $1^{\circ} \times 1^{\circ}$ grid as the observations for the comparison.
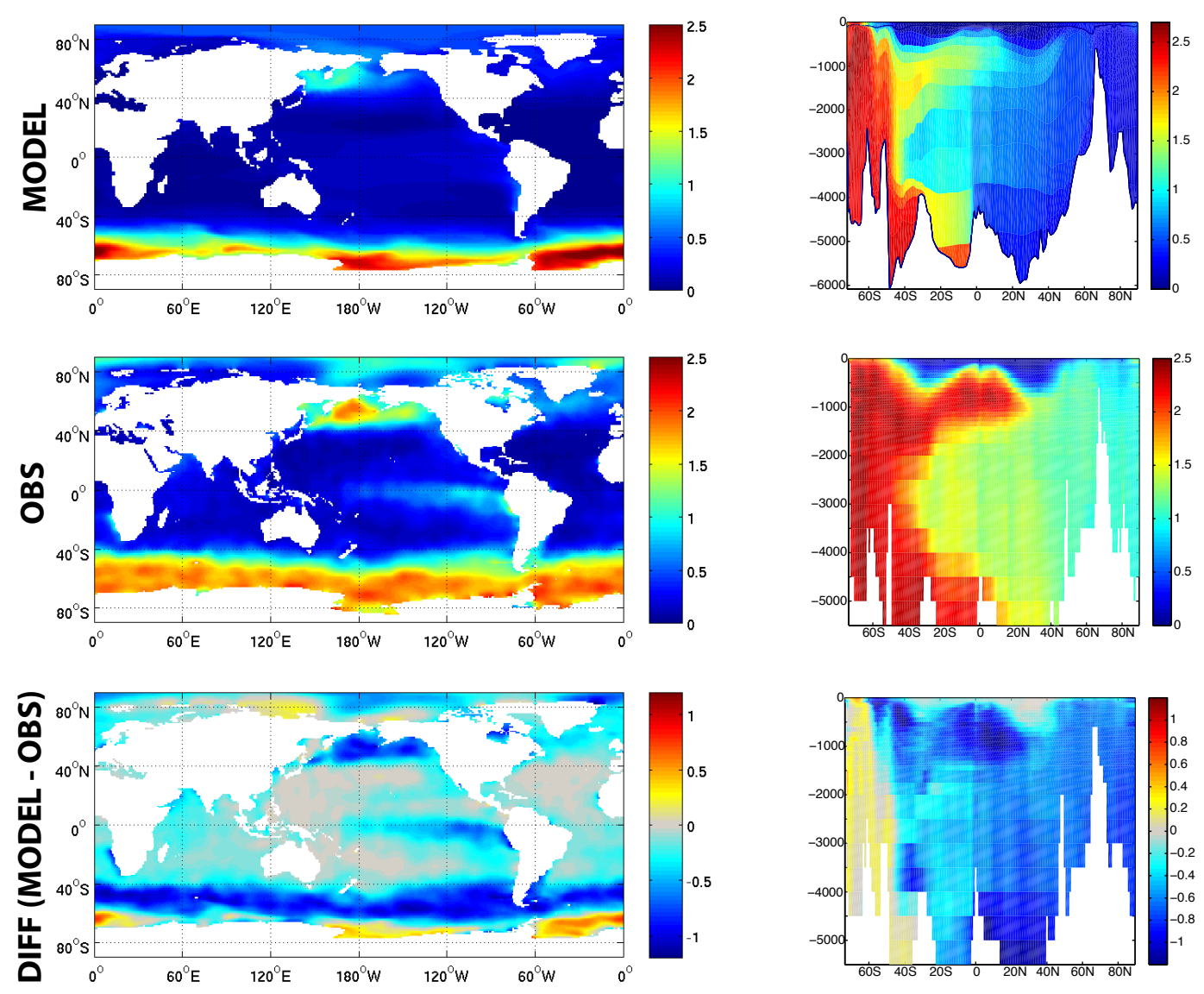

Fig. 10. As Fig. 3, but for phosphate $\left(\mu \mathrm{mol} 1^{-1}\right)$. 

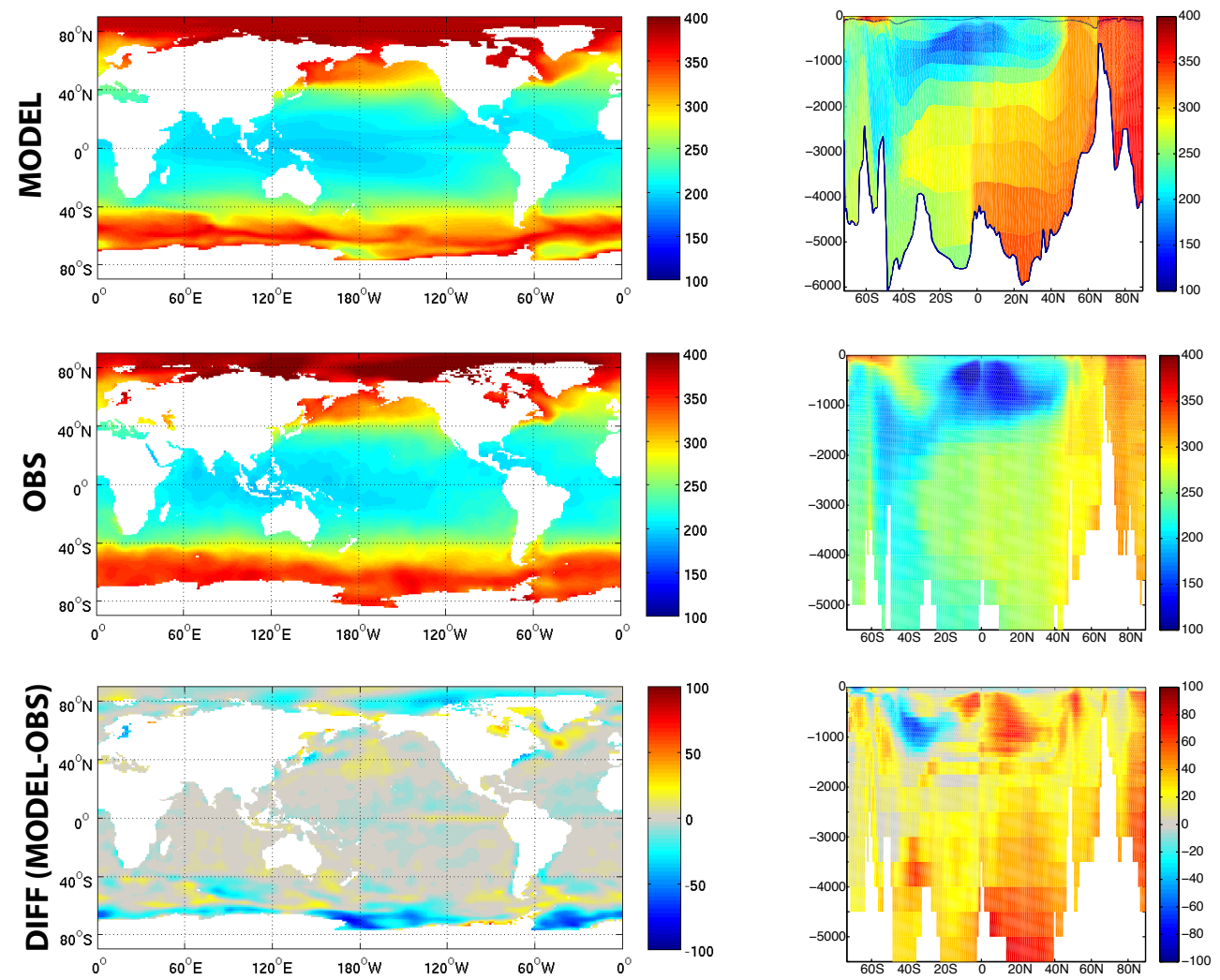

Fig. 11. As Fig. 3, but for oxygen $\left(\mu \mathrm{mol}^{-1}\right)$.
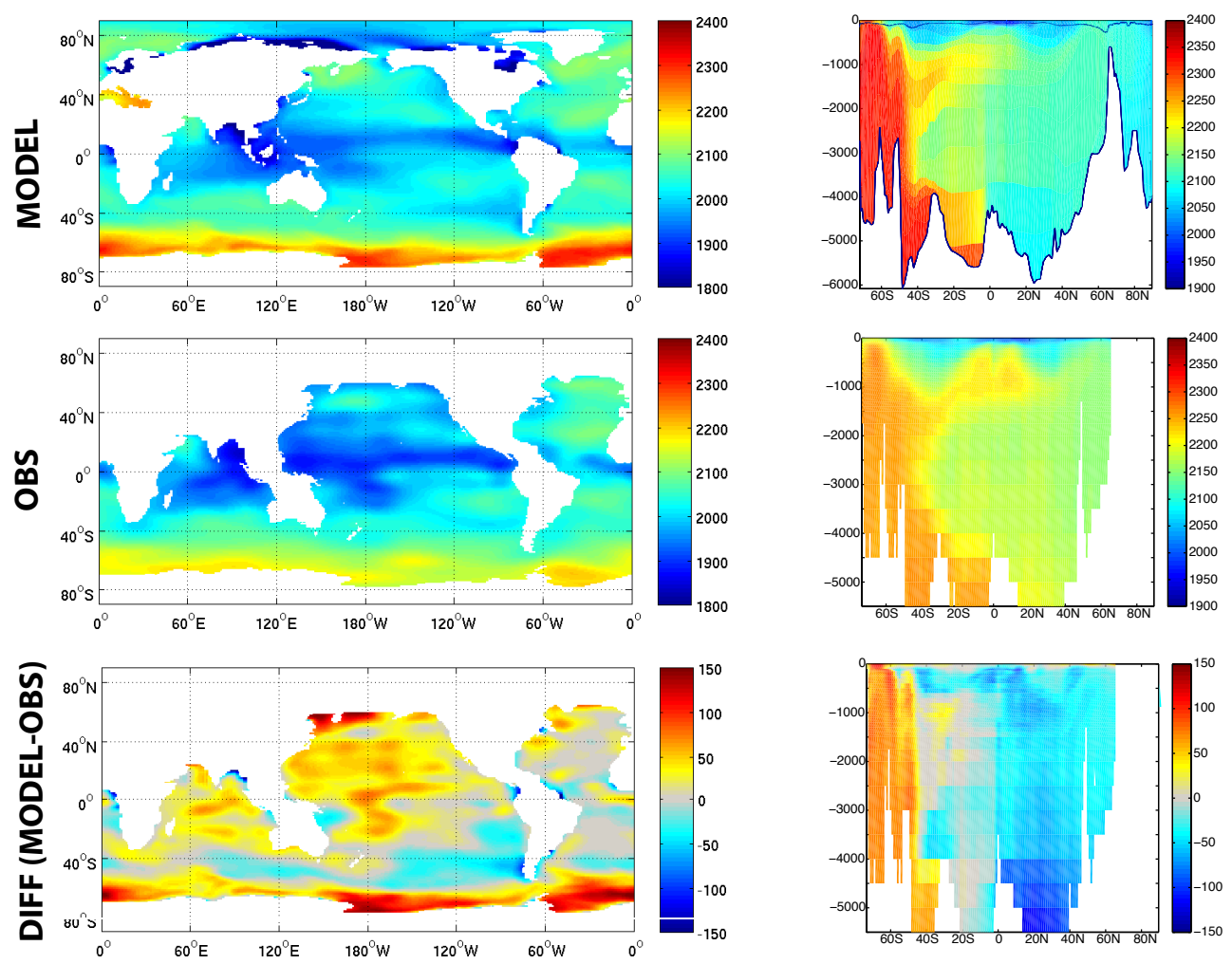

Fig. 12. As Fig. 3, but for DIC $\left(\mu \mathrm{mol} 1^{-1}\right)$. 


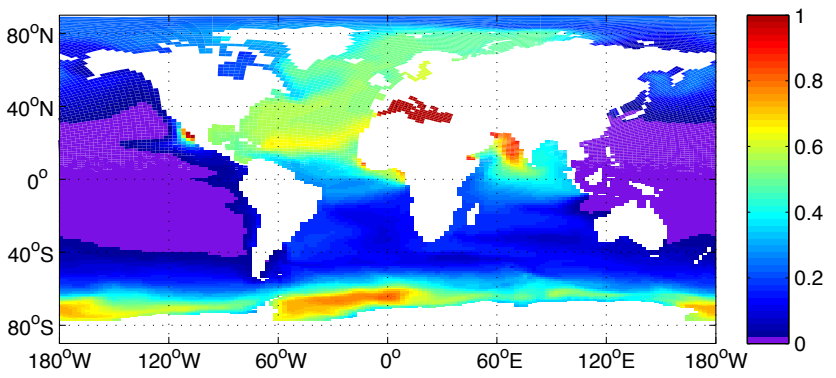

Fig. 13. Mean (1978-2007) simulated surface iron concentration in nmoll ${ }^{-1}$.

also affected by air-sea gas exchange and opal $/ \mathrm{CaCO}_{3}$ production. Again, the main feature is the trapping of carbon in the far Southern Ocean and low carbon in the North Atlantic Deep Water (NADW).

The simulated surface iron distribution (Fig. 13) clearly shows the high iron concentrations in the North Atlantic associated with Saharan dust deposition and lower surface iron concentrations in the Pacific. Elevated iron concentration along the coasts are confined to upwelling areas, while the remaining shelf seas have relatively low iron concentrations due to the missing sediment source of iron in HAMOCC. In a synthesis of observed surface iron concentrations in Moore et al. (2002), values in the Southern Ocean are found to vary widely between 0.05 and $3.8 \mathrm{nmoll}^{-1}$ and indicate that the relatively high iron concentration of up to $0.7 \mathrm{nmol}^{-1}$ found in this region in our simulation are not unrealistic. The global ocean iron inventory in our model is $7.97 \times 10^{11}$ moles Fe.

Global mean values for biological production are within observation-based estimates. Mean global primary production is $48.5 \pm 2.0 \mathrm{GtC} \mathrm{yr}^{-1}$, POC export production $12.4 \pm 0.53 \mathrm{GtC} \mathrm{yr}^{-1}$, calcium carbonate export $0.91 \pm 0.04 \mathrm{GtC} \mathrm{yr}^{-1}$ and silicate export 157.6 $4.2 \mathrm{Tmol} \mathrm{Si} \mathrm{yr}^{-1}$ (Treguer et al., 1995). The values for POC, opal and calcium carbonate export production are calculated at $90 \mathrm{~m}$, i.e., the depth of the HAMOCC euphotic zone. Our value for global primary production agrees well

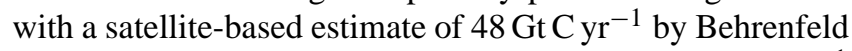
et al. (2006) and is within the range of $35-70{\mathrm{GtC} \mathrm{yr}^{-1}}^{-1}$ given by Carr et al. (2006). POC export production is at the higher end of observation-based estimates which range

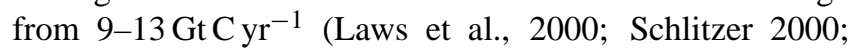
Dunne et al. 2007), and markedly higher than that in other contemporary ocean carbon cycle models (Dunne et al., 2007; Schneider et al., 2008).

The global distribution of primary and export production (Fig. 14) shows maxima in the North Atlantic and Pacific and in the coastal and equatorial upwelling regions, as expected (e.g. Schneider et al., 2008, Fig. 6). Biological production in the shallow shelf areas is underestimated as in most global models due to the lack of resolution and nutrient inputs by rivers and run-off. Due to the low nutrient supply to the
North Pacific and Atlantic, simulated biological production in these areas is also low. The most striking deviation from the observation-based distribution of primary and export production is the broad band of high production in the Southern Ocean reaching south to the simulated summer sea-ice edge. We will explore possible reasons for this in a series of sensitivity studies in Sect. 5 .

\section{Air-sea fluxes and the uptake of anthropogenic $\mathrm{CO}_{2}$}

There is a mean ocean carbon uptake of $0.05 \pm$ $0.006 \mathrm{GtC} \mathrm{yr}^{-1}$ in the reference simulation, CLIM (Fig. 15a). During this reference simulation, there is a small, statistically significant, negative trend of $-4.2 \times 10^{-5} \mathrm{GtC} \mathrm{yr}^{-1} \mathrm{yr}^{-1}$. While this indicates that the simulation would benefit from further integration, we conclude that it is sufficiently stable for use during a 150year integration including anthropogenic carbon emissions which leads to air-sea fluxes much larger than the small imbalance in the reference simulation. In the simulation forced by NCEP Reanalysis, SYN, annual ocean carbon

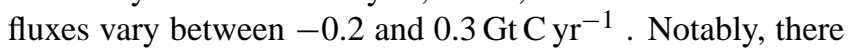
is a positive trend in the carbon fluxes in SYN after the late 1990s indicating that changes in the physical system reduce the ocean's ability to take up carbon. In the equivalent simulation including emissions, SYN + EMS, the increase in ocean carbon uptake slows after this point, while uptake in the CLIM + EMS simulation continuously forced by NCEP year 1959 increases more sharply due to an acceleration in anthropogenic emissions. Thus, our model results agree with recent findings of a weakening of the ocean carbon sink due to a climate-carbon cycle feedback (Schuster and Watson, 2007; Schuster et al., 2009; LeQuéré et al., 2007; Metzl, 2009).

Air-sea carbon flux climatologies, based on observations, estimate an ocean carbon uptake of $2.2 \pm 0.5 \mathrm{Gt} \mathrm{C} \mathrm{yr}^{-1}$ for 1995 (Takahashi et al., 2002) and in an updated version $1.4 \pm 0.7 \mathrm{Gt} \mathrm{C} \mathrm{yr}^{-1} \quad\left(2.0 \pm 0.7 \mathrm{GtC} \mathrm{yr}^{-1}\right.$ anthropogenic uptake) for 2000 (Takahashi et al., 2009). Simulated ocean uptake for these years is $2.8 \mathrm{GtC} \mathrm{yr}^{-1}$ and $2.7 \mathrm{GtC} \mathrm{yr}^{-1}$, respectively and, therefore, just outside upper bounds for the observational values. It is, however, worth noting that Takahashi et al. (2009) assume a preindustrial ocean carbon source of $0.4 \mathrm{GtC} \mathrm{yr}^{-1}$ which brings their estimate of anthropogenic carbon uptake closer to ours since the simulated 2000 flux without emissions in SYN is only $0.06 \mathrm{Gt} \mathrm{C} \mathrm{yr}^{-1}$.

A comparison of the observed year 2000 climatology and the simulated fluxes for the same year shows that the model underestimates outgassing in the upwelling regions like the equatorial Pacific (Fig. 16f). This is due to the underestimation of upwelling rates discussed in Sect. 3.1. In addition, uptake in the high latitude sink regions of the North Pacific, North Atlantic and Southern Ocean is generally overestimated. Reasons for this are likely associated with the 

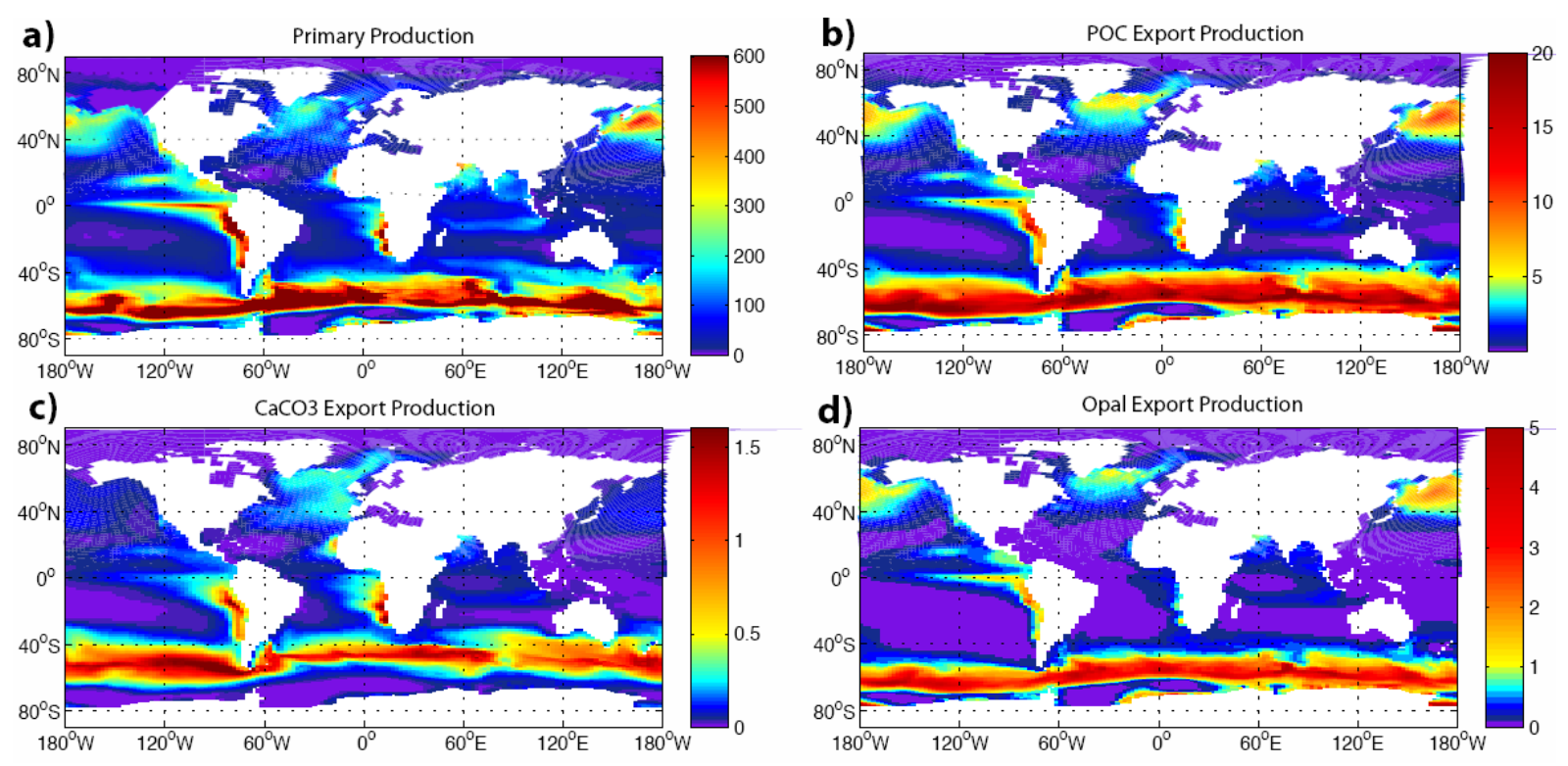

Fig. 14. Mean (1978-2007) simulated (a) primary production $\left(\mathrm{mol} \mathrm{C} \mathrm{m}^{-2} \mathrm{yr}^{-1}\right)$, (b) $\mathrm{POC}$ export production $\left(\mathrm{mol} \mathrm{C} \mathrm{m}^{-2} \mathrm{yr}^{-1}\right),(\mathbf{c}) \mathrm{CaCO}_{3}$ export $\left(\mathrm{mol} \mathrm{C} \mathrm{m}^{-2} \mathrm{yr}^{-1}\right)$, and (d) opal export (mol Si m$\left.{ }^{-2} \mathrm{yr}^{-1}\right)$.

artificially large vertical mixing in the model which allows fast subduction of carbon taken up particularly in winter and overestimated export production in the Southern Ocean. The fact that MICOM has a bulk mixed layer probably also contributes to this phenomenon: carbon taken up at the ocean surface is instantaneously mixed with a volume of water that is large, particularly in winter. The resulting changes to surface $p \mathrm{CO}_{2}$ are consequently small and further uptake is easily possible.

The Southern Ocean is the region with the largest disagreement between model and climatology. When the area south of $56^{\circ} \mathrm{S}$ is excluded, the correlation between simulated and observation-based air-sea fluxes and $\Delta p \mathrm{CO}_{2}$ patterns improves from 0.38 to 0.73 for $\Delta p \mathrm{CO}_{2}$ and from 0.55 to 0.68 for the air-sea fluxes. This is particularly striking for $\Delta p \mathrm{CO}_{2}$ since a thick perennial sea-ice cover in the model prohibits outgassing in the central Weddell Sea and leads to excessively high surface $\Delta \mathrm{CO}_{2}$ values. However, the observed climatology is likely summer-biased in this region which would lead to underestimated $\Delta p \mathrm{CO}_{2}$. There is also, as yet, no parametrisation of carbon fluxes through sea ice available for large-scale models. Observations indicate that these fluxes are large (Semiletov et al., 2004), but most ocean carbon cycle models represent sea ice as an impregnable lid making the interpretation of their results in sea-ice covered areas difficult.

Using NCEP Reanalysis after 1948 leads to an atmospheric $\mathrm{CO}_{2}$ about 2 ppm higher than in the experiment that was continuously forced with NCEP year 1959 (Fig. 15b). All models of the Climate Carbon Cycle Model Intercomparison Project ( $\mathrm{C}^{4} \mathrm{MIP}$ ) have a carbon cycle-climate feedback,
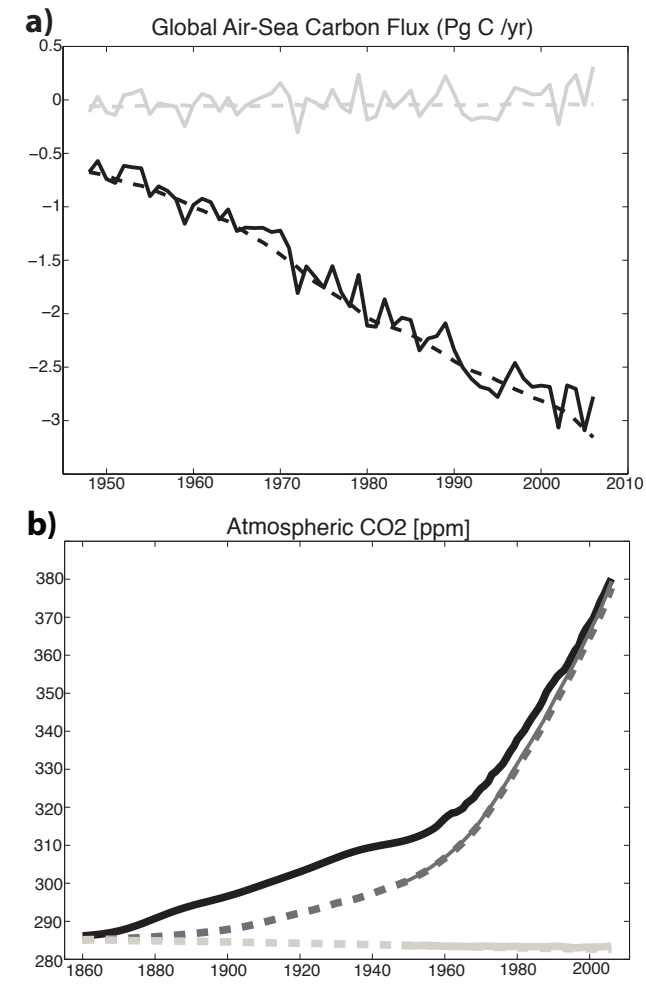

Fig. 15. (a) Time series of annual mean globally integrated airsea $\mathrm{CO}_{2}$ flux $\left(\mathrm{PgC} \mathrm{yr}^{-1}\right.$, negative downward). Black dashed CLIM + EMS, black solid SYN + EMS, light grey dashed CLIM, light grey solid SYN. (b) Time series of annual mean atmospheric $\mathrm{CO}_{2}$ concentrations 1860-2007 (ppm). Thick black line observed, dark grey dashed CLIM + EMS, dark grey solid SYN + EMS, light grey dashed CLIM, light grey solid SYN. 

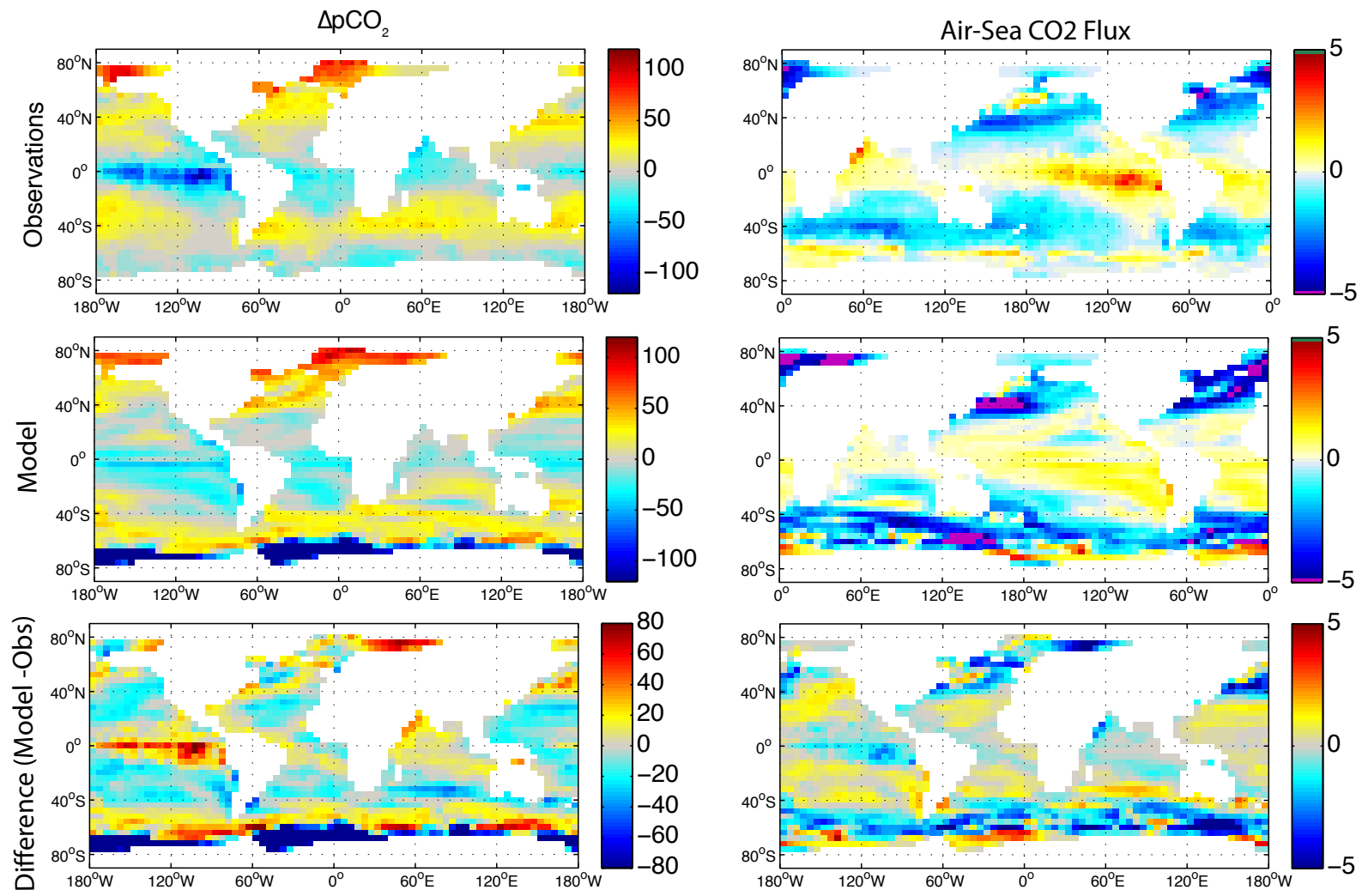

Fig. 16. Air-sea disequilibrium ( $\triangle p \mathrm{CO}_{2}$, ppm, left column) and $\mathrm{CO}_{2}$ fluxes (positive upward, $\mathrm{mol} \mathrm{C} \mathrm{m}^{-2} \mathrm{yr}^{-1}$, right column). Observations from Takahashi et al. (2009), referenced to 2000 (top), simulated mean for year 2000 (middle) and their difference (bottom). Model results were interpolated to the $4^{\circ} \times 5^{\circ}$ grid used by Takahashi et al. (2009).

i.e., the effect of global warming induced changes in the physical climate system on atmospheric $\mathrm{CO}_{2}$ levels, of less than $15 \mathrm{ppm}$ in 2006 (Friedlingstein et al., 2006) and this small effect is, therefore, not unreasonable for a stand-alone ocean model. Start and end values of the simulated time series are close to the observed values (Fig. 15b). However, the simulated atmospheric $\mathrm{CO}_{2}$ increases more slowly than that observed up to 1950, possibly because our model misses a land carbon model and a representation of the "pioneer effect" which made the land a significant carbon source during this period (Houghton, 1999). Towards the end of the 20th century, the simulated increase exceeds that observed, indicating a weakening of the ocean sink and a change of the land from source to sink. Of the $242.7 \mathrm{GtC}$ emitted between 1860 and 1994, the ocean in our model takes up $90 \mathrm{GtC}$, leaving $152.7 \mathrm{Gt} \mathrm{C}$ in the atmosphere. Both of these numbers are smaller than those deduced from observations by Sabine et al. (2004) due to the lack of the net land source in the model.

The column inventory of anthropogenic $\mathrm{CO}_{2}$ (Fig. 17) agrees well in pattern and magnitude with that deduced from observations by Sabine et al. (2004). Column inventories that exceed those of the observations may both be due to overestimated ventilation of the deep basins in the model

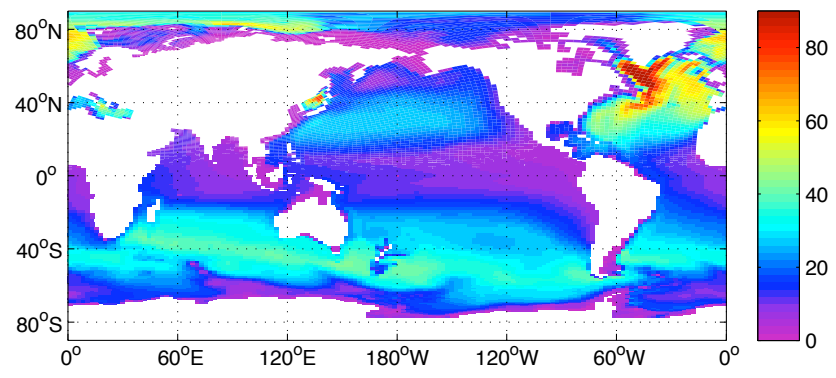

Fig. 17. Simulated column inventory of anthropogenic $\mathrm{CO}_{2}$ in the ocean $\left(\mathrm{mol} \mathrm{m}^{-2}\right)$ for 1994 in the SYN + EMS experiment. The correlation coefficient $R$ with the GLODAP data set (Sabine et al., $2005)$ is 0.75 .

and inaccuracies of the $\Delta C^{*}$ method used to deduce anthropogenic $\mathrm{CO}_{2}$ from the available observations (Matsumoto and Gruber, 2005). Underestimated column loads of anthropogenic $\mathrm{CO}_{2}$ in the tropical Atlantic can be explained both by the weak renewal of AAIW in the model and by the fact that our simulation misses emissions due to the "pioneer" effect early in the emission scenario which would have had time to penetrate further into the ocean interior. 


\section{Sensitivity studies}

One of the most striking deviations from observations in the model is the large biological production and the excessively high nutrients in the Southern Ocean, an area known as a HNLC-region (High Nutrient Low Chlorophyll). Biological production in the Southern Ocean is primarily limited by light and iron (e.g. Martin, 1990). Thus, we focus our sensitivity studies exploring the origin of the artificially large Southern Ocean primary production on these factors. We ran each of the sensitivity simulations for the NCEP period from 1948-2007 with anthropogenic $\mathrm{CO}_{2}$ emissions starting from year 1947 of the CLIM + EMS simulation, much like the setup of SYN + EMS simulation. We compare annual means for 2007 for each of the sensitivity runs to the same year in SYN + EMS. Since the model has not been run to equilibrium for each of these 60 year long simulations, the differences shown are indicative only of the sign of the changes and the relative magnitude, but not of the final magnitude of the induced changes and total feedback on the carbon cycle. The following sensitivity experiments were conducted:

- IRON: in this sensitivity study, we introduced a stronger iron limitation on the phytoplankton by changing $R_{\mathrm{Fe}: \mathrm{P}}$ from $R_{\mathrm{Fe}: \mathrm{P}}=3.7 \times 10^{-4}$ used in the standard $\mathrm{SYN}+$ EMS simulation to $R_{\mathrm{Fe}: \mathrm{P}}=6.1 \times 10^{-4}$ globally. This change causes the phytoplankton to take up more iron per unit phosphate, so that the available iron is depleted faster.

- ABS: HAMOCC uses the shortwave radiation incident at the upper interface of a layer to calculate biological production. In our standard model version, the entire mixed layer (or the part that is within the $90 \mathrm{~m}$ euphotic zone), therefore, receives the full shortwave radiation incident at the surface. To reduce biological production in regions with deep mixed layers in spring, the mixed layer is split virtually into a $20 \mathrm{~m}$ thick surface layer and the rest below this up to a maximum euphotic zone depth of $90 \mathrm{~m}$. Only the top $20 \mathrm{~m}$ receive the full incoming shortwave radiation, while the shortwave radiation incident on the lower part of the layer has been attenuated by absorption in the top $20 \mathrm{~m}$.

- DIAPYC: one issue in isopycnal models are layers that outcrop at the surface. In order to represent surface processes, a mixed layer with varying density is added in MICOM which contains these outcrops. Thus, there is an artificial diapycnal boundary between the isopycnal layers and their surface expression. Exchange across this boundary happens by changes in mixed layer thickness due to surface buoyancy fluxes and diapycnal mixing as used between the standard isopycnal layers. To account for the fact that fluxes between the mixed layer and the isopycnal layer are isopycnal rather than diapycnal, we increased the parameter $\mathrm{C}$ in the expression for the background diffusivity $v_{b}$ in Eq. (5) for the layer directly below the mixed layer by a factor of 10 .

In both IRON and ABS, export production decreases in a broad band between $40^{\circ} \mathrm{S}$ and the sea-ice edge (Fig. 18). In both cases, this coincides with an increase in phosphate concentrations in this area (Fig. 19) suggesting that the underestimation of phosphate concentration seen in Fig. 10 is due to excessive export production. However, the globally enhanced iron limitation leads to a significant and unrealistic increase in surface phosphate throughout the Pacific, South Atlantic and Indian Ocean. No change in phosphate is seen in IRON in the North Atlantic and Indian Ocean where large dust input from the Sahara leads to nitrate rather than iron limitation. Consequently, there is no change in export production in the North Atlantic in IRON, while there is a reduction in both the North and equatorial Pacific.

In ABS, increased surface phosphate (Fig. 19) in the North Pacific and Atlantic coincides with reduced export production (Fig. 18). While the former is a desirable improvement of the model results (Fig. 10), the latter is already underestimated in the standard model version. This indicates that we are possibly missing additional nutrient sources in these areas. The model only receives fresh water, but not the accompanying nutrient fluxes from the large Siberian rivers. These are suggested to be a significant source of nutrients in the North Atlantic (Jones et al., 2003), in addition to nutrient rich waters from the North Pacific that enter the Arctic and North Atlantic through Bering Strait. In the North Pacific, tidal mixing has been suggested as an important factor for transporting nutrient-rich intermediate waters into the surface layer to sustain vigorous biological production (Sarmiento et al., 2004). Our model, like most global OGCMs, does not include tides. However, the enhanced mixing between the surface and that layer directly below in DIAPYC lead to both enhanced export production and surface phosphate in this area (Figs. 18 and 19). This confirms that enhanced mixing is indeed needed to make the highly nutrient-rich deep and intermediate waters of the North Pacific accessible for biological production in the surface layer. In contrast, there is no significant effect in DIAPYC in the North Atlantic where waters directly below the surface are low in nutrients. Similarly to the North Pacific, enhanced diapycnal mixing between the mixed layer and sub-surface enhances both surface phosphate and export production in the Southern Ocean, extending both to just north of $40^{\circ} \mathrm{S}$. This northward extension brings our model distributions closer to observed ones and highlights the importance of exchange between the surface and intermediate as well as mode waters in this region. The strong increase of export production further south in DIAPYC may, in part, be due to the overestimated deep nutrient concentrations south of the ACC. 

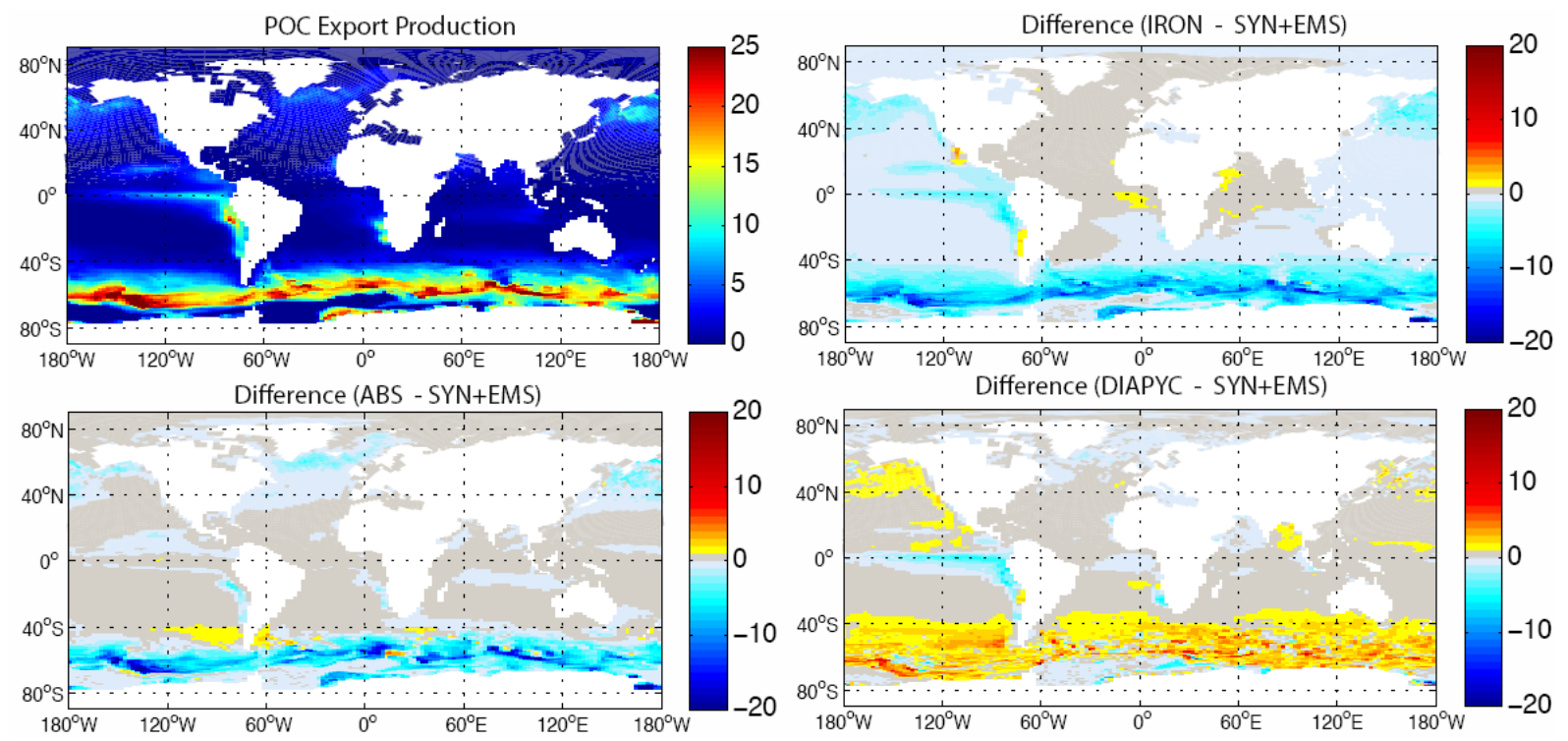

Fig. 18. POC export $\left(\mathrm{mol} \mathrm{C} \mathrm{m}^{-2} \mathrm{yr}^{-1}\right)$ for 2007 for $\mathrm{SYN}+\mathrm{EMS}$ as a reference and differences from this for IRON, ABS, and DIAPYC sensitivity experiments.
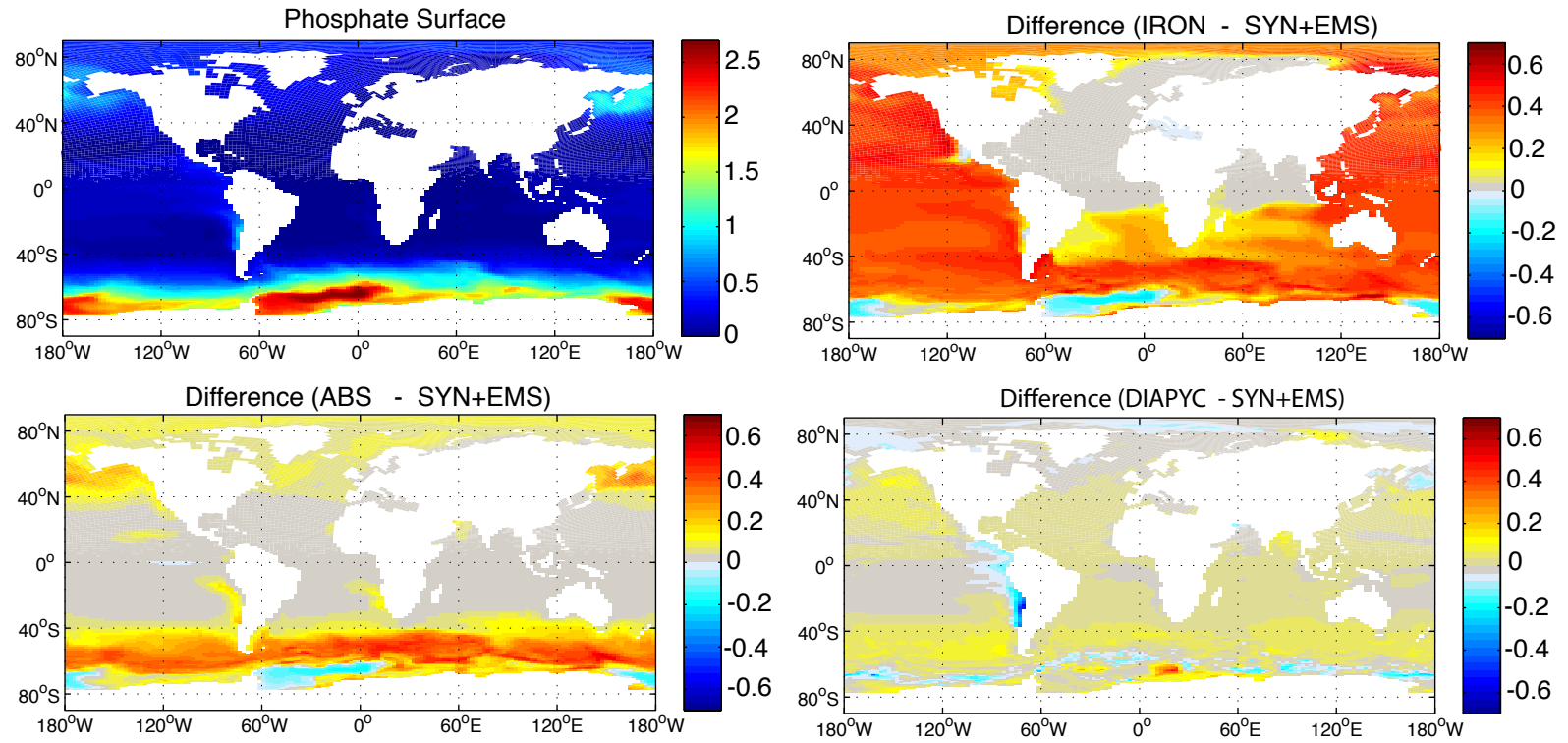

Fig. 19. Annual mean phosphate surface concentration $\left(\mu \mathrm{mol} 1^{-1}\right)$ for 2007 for $S Y N+$ EMS as a reference and differences from this for IRON, ABS and DIAPYC sensitivity experiments. 
Table 2. Production weighted nutrient limitation in percent of total primary production in the model for a 5-year mean (2003-2007).

\begin{tabular}{lcccccc}
\hline & PP & EP & Phosphate & Nitrate & Iron & $\begin{array}{c}\text { Light } \\
\text { and } \\
\text { Temp. } \\
\%\end{array}$ \\
& {$\left[\mathrm{Pg} \mathrm{C} \mathrm{yr}^{-1}\right]$} & {$\left[{\left.\mathrm{Pg} \mathrm{yr}^{-1}\right]}\right.$} & $\%$ & $\%$ & $\%$ & $\%$ \\
\hline SYN + EMS & 56.1 & 13.0 & 0.02 & 25.6 & 38.9 & 35.5 \\
IRON & 35.9 & 8.3 & 0.02 & 15.0 & 57.3 & 27.7 \\
ABS & 47.6 & 10.5 & 0.03 & 27.3 & 26.4 & 46.3 \\
DIAPYC & 66.7 & 15.3 & 0.01 & 23.1 & 43.1 & 33.8 \\
\hline
\end{tabular}

Evaluating the vertical phosphate distribution along a meridional section in the Atlantic, we found that while simulated concentrations south of the ACC are overestimated, concentrations in the AAIW and NADW are too low (Fig. 10). All sensitivity studies remedy the distribution in the Southern Atlantic by lowering nutrient concentrations in both CDW and AABW and increasing them in the AAIW and SAMW (Fig. 20). Decreasing export production in the IRON and ABS experiments leads to an increase of preformed surface phosphate in those regions where AAIW and SAMW are subducted. The decrease of fast-sinking detritus, that remineralises below the intermediate waters, lowers phosphate concentrations south of the ACC and finds a surface expression in a decrease of phosphate concentrations where these deep waters upwell underneath sea ice in the Weddell Sea. The existence of the same pattern in DIAPYC, albeit with a lesser reduction in the south, indicates that the main factor for the enhanced intermediate water concentrations is indeed the increased northward extension of both preformed nutrients and biological production.

To better understand the role of different limitations, we calculated production-weighted limitation from light, phosphate, nitrate and iron (Table 2). Hereby, the limiting nutrient was determined using the formulation used in HAMOCC

nutrient $=\min \left(\mathrm{PO}_{4}, \frac{\mathrm{NO}_{3}}{R_{\mathrm{N}: \mathrm{P}}}, \frac{\mathrm{Fe}}{R_{\mathrm{Fe}: \mathrm{P}}}\right)$

Following Schneider et al. (2008), primary production was considered to be light and temperature limited if the Michaelis-Menten term $\mathrm{MM}=N /(K+N)$, whereby $\mathrm{MM}$ is the Michaelis-Menten coefficient, $N$ the concentration of the limiting nutrient and $K$ the halfsaturation constant appropriate for the limiting nutrient, exceeded 0.7. In the reference run approximately equal proportions $(35-40 \%)$ of the production are light and iron limited and the remaining $25 \%$ by nitrate (Table 2). Phosphate limitation only occurs in small areas of the Mediterranean (Fig. 21) and will be neglected in the rest of this discussion since it only limits around $0.02 \%$ of the global primary production. Schneider et al. (2008) argued that the strong iron limitation used in the version of HAMOCC coupled to MPI-OM leads to the almost exclusive iron limitation of primary production in this model. In the IRON sensitivity study, which uses the same strong iron limitation as the HAMOCC version presented in Schneider et al. (2008) the percentage of production limited by iron increases to $57.3 \%$. Even though large areas of the South Indian, South Atlantic and Arctic Oceans are iron limited in this sensitivity study (Fig. 21), nitrate and light limitation is distinctly more prevalent in our IRON sensitivity study than in the HAMOCC + MPI-OM model run presented in Schneider et al. (2008). This indicates that the use of different physical models leads to significant differences in the biogeochemical fields. Increased supply of nutrients in the DIAPYC run causes mainly an increase in global primary and export production, but does not lead to significant shifts in production weighted limitations or their global distribution. A $12 \%$ increase in light and temperature limited production and corresponding decrease in iron limitation is seen in the ABS run. Areas that are light and temperature limited in this sensitivity study compared to the reference run are the Nordic and Barents Seas, but also a zonal band that extends to $40^{\circ} \mathrm{S}$ in the Southern Ocean.

\section{Discussion}

We have presented a new ocean carbon cycle model consisting of the isopycnic ocean model MICOM and the biogeochemistry model HAMOCC. After a thorough evaluation, we conclude that it is well-suited for global carbon cycle studies. The strength of an isopycnic vertical coordinate lies in it being a close approximation to the surfaces on which tracer transport in the interior ocean actually takes place. We find that our model reproduces, e.g., the invasion of anthropogenic carbon into the interior ocean well.

A disadvantage of the isopycnic coordinates lies in the need to use a mixed layer of varying density to handle layer outcropping at the ocean surface and air-sea exchange processes. MICOM uses a bulk mixed layer which implies that vertical resolution at the ocean surface is limited. It is, therefore, not particularly suited to detailed surface-ocean ecosystem studies that require a highly resolved euphotic zone. A relatively simple ecosystem model like the one in HAMOCC is, therefore, a good match to MICOM. Most of 

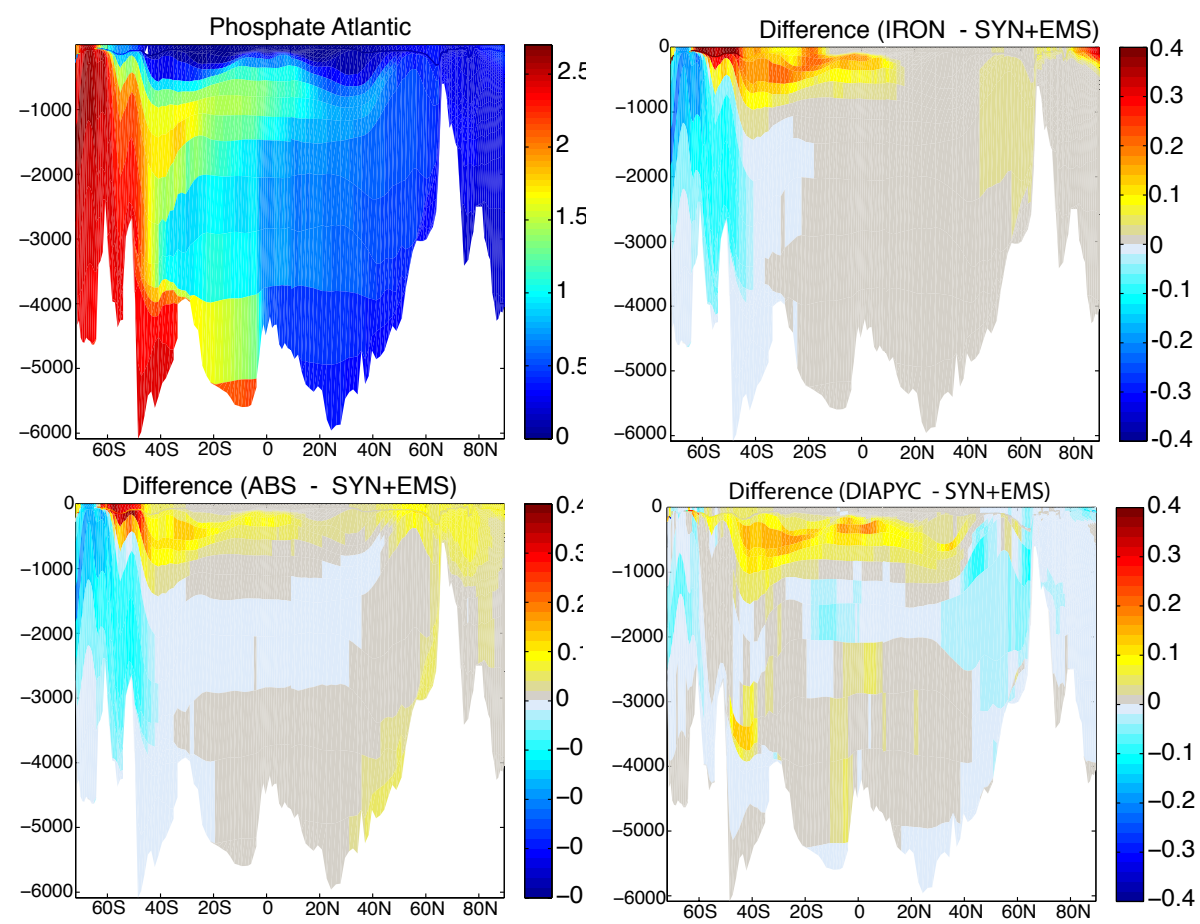

Fig. 20. Annual mean phosphate concentration along a meridional section in the western Atlantic ( $\mu \mathrm{mol}^{-1}$ ) for 2007 for SYN + EMS as a reference and differences from this for IRON, ABS and DIAPYC sensitivity experiments.
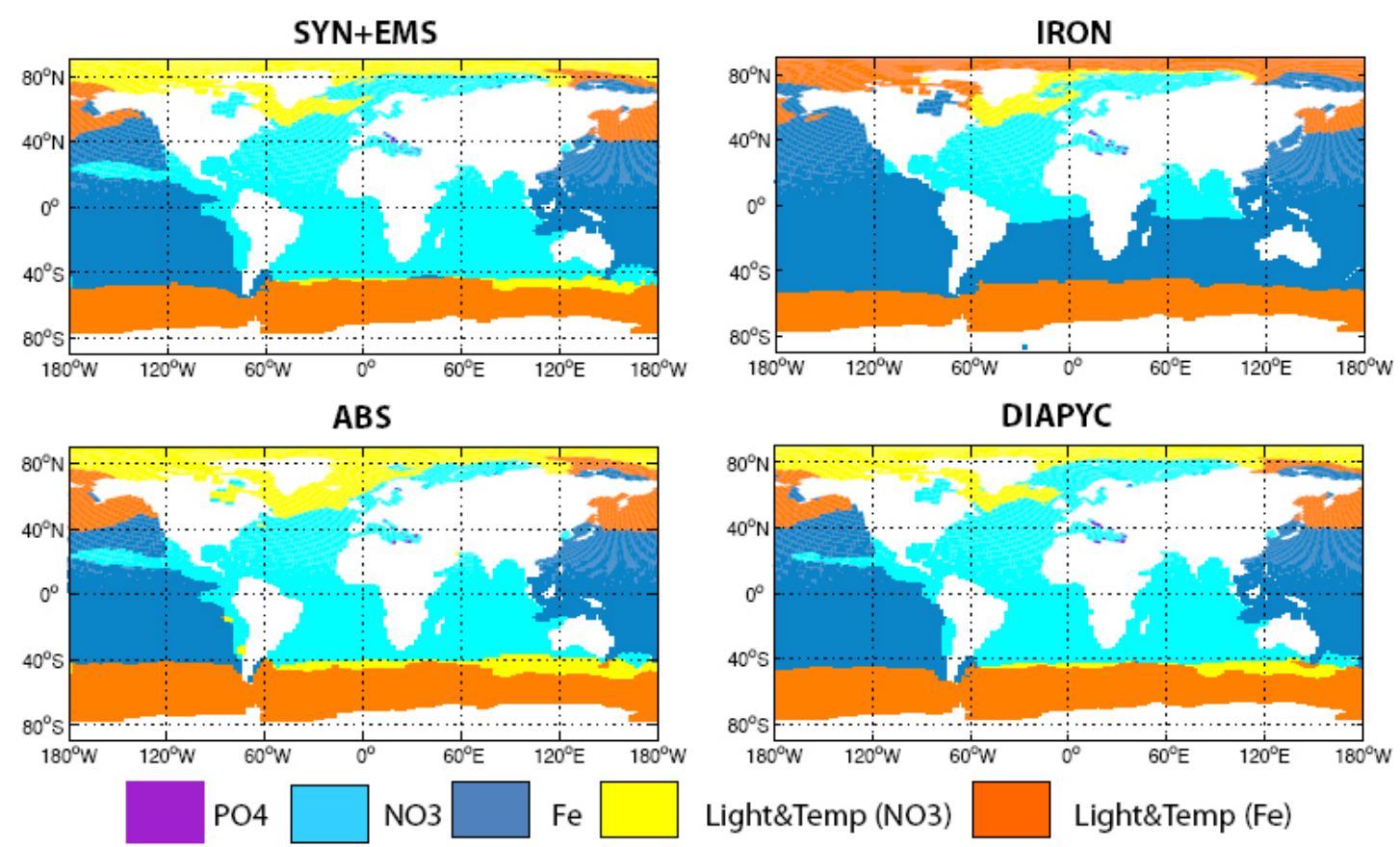

Fig. 21. Maps of factors limiting phytoplankton growth in the reference simulation and the sensitivity studies for a 2003-2007 mean. For nutrients the most limiting nutrient is shown, while for areas where light and temperature are limiting biological production, i.e., the value of the Michaelis-Menten term is above 0.7 (see Schneider et al., 2008 and explanations in the text) both this limitation and the limiting nutrient (in brackets) are indicated. 
the adaptation needed to make HAMOCC compatible with an isopycnic vertical coordinate was indeed in representing biological processes in the euphotic zone, e.g., phytoplankton growth and light absorption. A hybrid-coordinate model like HYCOM (Bleck, 2002), where the surface layer is split into closely spaced z-levels, is the better tool where dedicated ecosystem studies are concerned.

A series of sensitivity studies were performed with the purpose of exploring the origin of several model shortcomings like the vigorous biological production in the Southern Ocean. A result common to all of these is the importance of the distribution of preformed nutrients in the Southern Ocean on the global nutrient distribution as highlighted by Sarmiento et al. (2004) and Marinov et al. (2006). The overestimated biological production in our reference model experiment depletes surface nutrients leading to low nutrient concentrations in the AAIW. Instead, these nutrients sink into the upwelling CDW where they are remineralised and trapped within the unproductive southern loop of the MOC (Marinov et al., 2006). Reducing this export by both enhanced iron limitation and a more sophisticated light absorption scheme leads to a reduction in phosphate in this southern loop and an increase in nutrients in mode and intermediate waters. While enhanced diapycnal mixing between the mixed layer and the isopycnic layer immediately below leads to an increase in export production in the Southern Ocean, it produces the same pattern as the biogeochemical changes in the phosphate distribution, since it is also a mechanism that increases surface nutrients in the mode and intermediate water formation regions.

From the large-scale surface increase in phosphate in IRON, we conclude that this approach is either too simplistic or that iron is not at the root of the problem. Our standard iron to phosphate ratio corresponds to an iron to carbon ratio of $R_{\mathrm{Fe}: \mathrm{C}}=3 \times 10^{-6}$. This appears to be realistic compared to that of Sarthou et al. (1997) who derived an iron to carbon uptake ratio of $R_{\mathrm{Fe}: \mathrm{C}}=3.47 \times 10^{-6}$ from observations in the Indian Sector of the Southern Ocean and modelled iron concentrations that agreed with available observations (Moore and Braucher, 2008). If iron were to be the solution, uptake ratios would have to vary with either species or location, which they probably do. However, observations of iron and its uptake in plankton are sparse and, therefore, a wellvalidated parametrisation is hard to come by. In any case, it would probably go beyond the level of complexity of the rest of our biogeochemical model.

As discussed above, most of the challenges in adapting an ocean biogeochemistry module for use with an isopycnic coordinate lay in making it suitable for use with a bulk mixed layer. An important point here was light absorption. While we explored various parametrisations during model development, we settled on a fairly simple formulation that stayed close to the original formulation in HAMOCC for our reference run. The ABS sensitivity run indicates that using this simple parametrisation induces the excessive bio- logical production in the Southern Ocean and is sub-optimal for use in an isopycnic model with a bulk mixed layer. An improved parametrisation of light absorption in HAMOCC made a large impact on our results and will be used in further studies.

In the evaluation of our model results the effect of sea ice on biogeochemical processes and its representation as an impregnable lid - while air-sea fluxes are scaled to the open water portion of a grid box, high sea ice concentration which exist through much of the ice pack effectively prohibit airsea exchange - was touched upon several times. There is mounting evidence that sea ice is not simply a lid to air-sea exchange and biology (Semiletov et al., 2004), but more sophisticated parametrisations are necessary to include this in ocean carbon cycle and Earth System Models. Motivated by excessive DIC values under sea ice, particularly in the Southern Ocean, we allowed some exchange through sea ice by limiting the maximum sea-ice concentration that HAMOCC experiences to 0.5 . More permeable sea ice would allow outgassing of some of this carbon and some biological production, attempting to counteract the overestimated summer sea ice extent in the Southern Ocean. After a 60 year simulation the effects are still largely confined to sea-ice covered areas. Changes to atmospheric $\mathrm{CO}_{2}$, ocean carbon uptake and export production are not significant. There is a substantial reduction in phosphate in Arctic surface waters that extends into the Labrador Sea where it is subducted into the deep ocean. This implies that Arctic waters play an important role in North Atlantic nutrient supply. Missing nutrient inputs from Arctic rivers (e.g. McClelland et al., 2006) and an underestimated Pacific water layer (Falck et al., 2005; Jones et al., 2003) may explain the low nutrient concentrations and biological production in these regions in our model. The overestimated Antarctic summer sea-ice extent is mainly caused by the erosion of the warm CDW core by excessive mixing. The problem was addressed in a more recent model version by using in situ instead of potential density at $2000 \mathrm{db}$ to assess the stability of the water column. In addition, we now use the mixed-layer formulation by Oberhuber (1993) instead of Gaspar (1988) and have added mass field and isopycnal eddy mixing.

Based on this evaluation, we conclude that the new isopycnic ocean carbon cycle model, we have presented here, is a useful tool to investigate ocean biogeochemistry processes and their interaction with the physical system. It has been included in the Bergen Climate Model and first results prove that its capabilities in projecting the climate system's response to anthropogenic $\mathrm{CO}_{2}$ emissions lie well within the bounds of other coupled carbon cycle-climate models (Tjiputra et al., 2009). Work on a new model version currently in progress includes some of the parametrisations explored in our sensitivity studies as well as a parametrisation of vertical mixing that circumvents the issue of unstable Southern Ocean sub-surface stratification associated with a $2000 \mathrm{~m}$ reference pressure. 
Acknowledgements. We would like to thank Anand Gnanadesikan and two anonymous reviewers for constructive reviews that greatly helped to improve the manuscript. This study at the University of Bergen and Bjerknes Centre for Climate Research is supported by the EU-FP6 integrated project CarboOcean (grant nr. 511176), and the Research Council of Norway funded projects MerClim and CarbonHeat. We also acknowledge the Norwegian Metacenter for Computational Science and Storage Infrastructure (NOTUR, Biogeochemical Earth system modelling project nn2980k) for providing the computing resources essential for this study. This is publication no. A278 from the Bjerknes Centre for Climate Research.

Edited by: A. Ridgwell

\section{References}

Archer, D.: Fate of fossil fuel $\mathrm{CO}_{2}$ in geologic time, J. Geophys. Res., 110, C09S05, doi:10.1029/2004JC002625, 2005.

Archer, D. and Maier-Reimer, E.: Effect of deep-sea sedimentary calcite preservation on atmospheric $\mathrm{CO}_{2}$ concentration, Nature, 367, 260-263, 1994.

Assmann, K. M. and Timmermann, R.: Variability of dense water formation in the Ross Sea, Ocean Dynam., 55, 68-87, 2005.

Aumont, O., Maier-Reimer, E., Blain, S., and Monfray, P.: An ecosystem model of the global ocean including $\mathrm{Fe}$, Si, P colimitations, Global Biogeochem. Cy., 17, 1060, doi:10.1029/2001GB001745, 2003.

Aumont, O., Orr, J. C., Monfray, P., Madec, G., and Meier-Reimer, E.: Nutrient trapping in the Equatorial Pacific: the ocean circulation solution, Global Biogeochem. Cy., 13(2), 351-369, 1999.

Bacastow, R. and Maier-Reimer, E.: Ocean-circulation model of the carbon cycle, Clim. Dynam., 4, 95-125, 1990.

Beckmann, A., Hellmer, H. H., and Timmermann, R.: A numerical model of the Weddell Sea: large scale circulation and water mass distribution, J. Geophys. Res., 104(C10), 23375-23391, 1999.

Behrenfeld, M. J., O’Malley, R. T., Siegel, D. A., et al.: Climatedriven trends in contemporary ocean productivity, Nature, 444, 752-755, 2006.

Bentsen, M., Evensen, G., Drange, H., and Jenkins, A. D.: Coordinate Transformation on a Sphere Using Conformal Mapping, Mon. Weather Rev., 127, 2733-2740, 1999.

Bentsen, M. and Drange, H.: Parameterizing surface fluxes in ocean models using the NCEP/NCAR reanalysis data, RegClim General Technical Report No. 4, Norwegian Institute for Air Research, 149-158, 2000.

Bentsen, M., Drange, H., Furevik, T., and Zhou, T.: Simulated variability of the Atlantic meridional overturning circulation, Clim. Dynam., 22, 701-720, 2004.

Berliand, M. and Berliand, T.: Determining the net long-wave radiation of the earth with consideration of the effect of cloudiness, Isv. Akad. Nauk. SSSR Ser. Geofis., 1, 1952.

Bleck, R. and Smith, L. T.: A Wind-Driven Isopycnic Coordinate Model of the North and Equatorial Atlantic Ocean. 1. Model Development and Supporting Experiments, J. Geophys. Res., 95(C3), 3273-3285, 1990.

Bleck, R.: An oceanic general circulation model framed in hybrid isopycnic-cartesian coordinates, Ocean Model., 4, 55-88, 2002.
Bleck, R., Rooth, C., Hu, D., and Smith, L. T.: Salinity-driven Thermocline Transients in a Wind- and Thermohaline-forced Isopycnic Coordinate Model of the North Atlantic, J. Phys. Oceanogr., 22, 1486-1505, 1992.

Boden, T. A., Marland, G., and Andres, R. J.: Global, regional, and national $\mathrm{CO}_{2}$ emissions, in: Trends: A compendium of data on global change, Carbon Dioxide Information Analysis Center, US Department of Energy, Oak Ridge, TN, USA, doi:10.3334/CDIAC/00001, 2009.

Bolin, B. and Eriksson, E.: Changes in the carbon dioxide content of the atmosphere and sea due to fossil fuel combustion, in: The atmosphere and the sea in motion, Rossby Memorial Volume, edited by: Bolin, B., Rockefeller Inst., New York, 130-142, 1957.

Boyer, T. P., Antonov, J. I., Garcia, H. E., Johnson, D. R., Locarnini, R. A., et al.: World Ocean Database 2005, edited by: Levitus, S., NOAA Atlas NESDIS 60, US Government Printing Office, Washington, DC, 190 pp., DVDs, 2006.

Buch, K., Harvey, H. W., Wattenberg, H., and Gripenberg, S.: Über das Kohlensäuresystem im Meerwasser, Conseil.Perm. Internat. p. l'Explor. de la Mer, Rapp. et Proc.-Verb., 79, 70 pp., 1932.

Caldeira, K. and Wickett, M. E.: Anthropogenic carbon and ocean pH, Nature, 425, p. 365, 2003.

Carr, M.-E., Friedrichs, M. A. M., Schmetz, M., et al.: A comparison of global estimates of marine primary production from ocean colour, Deep-Sea Res., 53, 741-770, 2006.

de Szoeke, R .A.: Equations of Motion Using Thermodynamic Coordinates, J. Phys. Oceanogr., 30, 2814-2829, 2000.

Denman, K. L., Brasseur, G., Chidthaisong, A., Ciais, P., Cox, P. M., et al.: Couplings Between Changes in the Climate System and Biogeochemistry, in: Climate Change 2007: The Physical Science Basis. Contribution of Working Group I to the Fourth Assessment Report of the Intergovernmental Panel on Climate Change, edited by: Solomon, S., Qin, D., Manning, M., Chen, Z., Marquis, M., Averyt, K. B., Tignor, M., and Miller, H. L., Cambridge University Press, Cambridge, UK and New York, NY, USA, 2007.

Doney, S. C., Lindsay, K., Caldeira, K., Campin, J.-M., Drange, H., et al.: Evaluating global ocean carbon models: The importance of realistic physics, Global Biogeochem. Cy., 18, GB3017, doi:10.1029/2003GB002150, 2004.

Drange, H.: A 3-dimensional isopycnic coordinate model of the seasonal cycling of carbon and nitrogen in the Atlantic Ocean, Phys. Chem. Earth, 21(5-6), 503-509, 1996.

Drange, H. and Simonsen, K.: Formulation of Air-Sea Fluxes in the ESOP2 Version of MICOM, Nansen Environmental and Remote Sensing Center, Bergen, Norway, Technical Report 125, 23 pp., 1996.

Drange, H., Gerdes, R., Gao, Y., Karcher, M., Kauker, F., and Bentsen, M.: Ocean general circulation modelling of the Nordic Seas, in: The Nordic Seas: An integrated perspective, edited by: Drange, H., Dokken, T., Furevik, T., Gerdes, R., and Berger, W., American Geophysical Union, Washington DC, Monograph, 158, 366 pp., 2005.

Duce, R. A., LaRoche, J., Altieri, K., Arrigo, K. R., Baker, A. R., et al.: Impacts of Atmospheric Anthropogenic Nitrogen on the Open Ocean, Science, 320, 893-897, 2008.

Dukowicz, J. K. and Baumgardner, J. R.: Incremental Remapping as a Transport/Advection Algorithm, J. Comput. Phys., 160, 
318-335, 2000.

Dunne, J. P., Sarmiento, J. L., and Gnanadesikan, A.: A synthesis of global particle export from the surface ocean and cycling through the ocean interior and on the seafloor, Global Biogeochem. Cy., 21, GB4006, doi:10.1029/2006GB002907, 2007.

Eppley, R. W.: Temperature and phytoplankton growth in the sea, Fish. B.-NOAA, 70, 1063-1085, 1972.

Fairall, C., Bradley, E., Rogers, D., Edson, J., and Young, G.: Bulk parameterization of air-sea fluxes for tropical oceanglobal atmosphere coupled ocean atmosphere response experiment, J. Geophys. Res., 101, 3747-3764, 1996.

Falck, E., Kattner, G., and Budeus, G.: Disappearance of Pacific Water in the northwestern Fram Strait, Geophys. Res. Lett., 32, L14619, doi:10.1029/2005GL023400, 2005.

Fasham, M. J. R., Ducklow, H. W., and McKelvie, S. M.: A nitrogen based model of plankton dynamics in the ocean mixed layer, J. Mar. Res., 48, 591-639, 1990.

Feistel, R.: A new extended Gibbs thermodynamic potential of seawater, Prog. Oceanogr., 58, 43-114, 2004.

Friedlingstein, P., Cox, P., Betts, R., Bopp, L., von Bloh, W., et al.: Climate Carbon Cycle Feedback Analysis: Results from the C4MIP Model Intercomparison, J. Climate, 19, 3337-3353, doi: 10.1175/JCLI3800.1, 2006.

Furevik, T., M. Bentsen,Drange, H., I. K. T. Kindem, N. G. Kvamst $\varnothing$, and A. Sorteberg: Description and evaluation of the Bergen Climate Model: ARPEGE coupled with MICOM, Clim. Dynam., 21, 27-51, 2003.

Gao, Y., Drange, H., Bentsen, M., and Johannessen, O.: Tracerderived transit time of the waters in the eastern Nordic Seas, Tellus B, 57, 332-340, 2005.

Gargett, A. E.: Vertical eddy diffusivity in the ocean interior, J. Mar. Res., 42, 359-393, 1984.

Gaspar, P.: Modeling the Seasonal Cycle of the Upper Ocean, J. Phys. Oceanogr., 18, 161-180, 1988.

Gehlen, M., Bopp, L., and Aumont, O.: Short-term dissolution response of pelagic carbonate sediments to the invasion of anthropogenic $\mathrm{CO}_{2}$ : A model study, Geochem. Geophysics Geosystems, 9(2), Q02012, doi:10.1029/2007GC001756, 2008.

Gnanadesikan, A.: Numerical issues for coupling biological models with isopycnal mixing schemes, Ocean Model., 1, 1-15, 1999.

Gnanadesikan, A., Dunne, J. P., Key, R. M., Matsumoto, K., Sarmiento, J. L., Slater, R. D., and Swathi, P. S.: Oceanic ventilation and biogeochemical cycleng: Understanding the physical mechanisms that produce realistic distributions of tracers and productivity, Global Biogeochem. Cy., 18, GB4010, doi:10.1029/2003GB002097, 2004.

Griffies, S. M., Böning, C., Bryan, F. O., Chassignet, E. P., Gerdes, R., Hasumi, H., Hirst, A., Treguier, A.-M., and Webb, D.: Developments in ocean climate modelling, Ocean Model., 2, 123-192, 2000.

Griffies, S. M., Pacanowski, R. C., and Hallberg, R. W.: Spurious diapycnal mixing associated with advection in a $\mathrm{Z}$-coordinate ocean model, Mon. Weather Rev., 128, 538-564, 2000.

Griffies, S. M., Biastoch, A., Böning, C., Bryan, F., et al.: Coordinated Ocean-ice Reference Experiments (COREs), Ocean Model., 26, 1-46, 2009.

Hallberg, R.: A thermobaric instability of Lagrangian vertical coordinate ocean models, Ocean Model., 8(3), 279-300, 2005.
Harder, M.: Dynamik, Rauhigkeit und Alter des Meereises in der Arktis, Alfred-Wegener-Institut für Polar- und Meeresforschung, Bremerhaven, Germany, 124 pp., 1996.

Hatùn, H., Sandø, A.-B., Drange, H., Hansen, B., and Valdimarsson, H.: Influence of the Atlantic subpolar gyre on the thermohaline circulation. Science, 309, 1841-1844, 2005.

Heinze, C., Maier-Reimer, E., Winguth, A. M. E., and Archer, D.: A global oceanic sediment model for long-term climate studies, Global Biogeochem. Cy., 13(1), 221-250, 1999.

Hibler III, W. D.: A Dynamic Thermodynamic Sea Ice Model, J. Phys. Oceanogr., 9, 815-846, 1979.

Houghton, R. A.: The annual net flux of carbon to the atmosphere from changes in land use 1850-1990, Tellus B, 51, 298-313, 1999.

Hsu, Y. G. and Arakawa, A.: Numerical Modeling of the Atmosphere with an Isentropic Vertical Coordinate, Mon. Weather Rev., 118, 1933-1959, 1990.

Jackett, D. R., McDougall, T. J., Feistel, R., Wright, D. D., and Griffies, S. M.: Algorithms for Density, Potential Temperature, Conservative Temperature and the Freezing Temperature of Seawater, J. Atmos. Ocean. Tech., 23(12), 1709-1728, 2006.

Janjić, Z. I.: Pressure gradient force and advection scheme used for forecasting with steep and small scale topography, Beiträge zur Physik der Atmosphäre, 50, 186-199, 1977.

Jickells, T. D., An, Z. S., Andersen, K. K., Baker, A. R., Bergametti, G., et al.: Global Iron Connections Between Desert Dust, Ocean Biogeochemistry, and Climate, Science, 308, 67-71, 2005.

Johnson, K. S., Gordon, R. M., and Coale, K. H.: What controls dissolved iron concentrations in the world ocean?, Mar. Chem., 57, 137-161, 1997.

Jones, E. P., Swift, J. H., Anderson, L. G., Lipizer, M., Civitarese, G., Falkner, K. K., Kattner, G., and McLaughlin, F.: Tracing Pacific Water in the North Atlantic Ocean, J. Geophys. Res., 108(C4), 3116, doi:10.1029/2001JC001141, 2003.

Kalnay, E., Kanamitsu, M., Kistler, R., et al.: The NCEP/NCAR 40Year Reanalysis Project, B. Am. Meteorol. Soc., 77, 437-471, 1996.

Kraus, E. B. and Turner, J. S.: A one-dimensional model for the seasonal thermocline. II. The general theory and its consequences, Tellus, 14, 98-105, 1967.

Laws, E. A., Falkowski, P. G., Smith, W. O., and Ducklow, H.: Temperature effects on export production in the open ocean, Global Biogeochem. Cy., 14(4), 1231-1246, 2000.

LeQuéré, C., Harrison, S. P., Prentice, I. C., Buitenhuis, E. T., Aumont, O., et al.: Ecosystem dynamics based on plankton functional types for global ocean biogeochemistry models, Glob. Change Biol., 11, 2016-2040, doi:10.1111/j.13652486.2005.01004.x, 2005.

LeQuéré, C., Rödenbeck, C., Buitenhuis, E. T., Conway, T. J., et al.: Saturation of the Southern Ocean $\mathrm{CO}_{2}$ sink due to recent climate change, Science, 316, 1735-1738, 2007.

Levitus, S. and Boyer, T.: World Ocean Atlas 1994: temperature, NOAA Atlas NESDIS 4, US Department of Commerce, Washington, DC, 4, 117 pp, 1994.

Levitus, S., Burgett, R., and Boyer, T.: World Ocean Atlas 1994, volume 3: salinity, NOAA Atlas NESDIS 3, US Department of Commerce, Washington, DC, 99 pp., 1994.

Liu, X. D., Osher, S., and Chan, T.: Weighted Essential NonOscillatory Schemes, J. Comput. Phys., 115 , 200-212, 1994. 
Lohmann, K., Drange, H., and Bentsen, M.: Response of the North Atlantic subpolar gyre to persistent North Atlantic Oscillation like forcing, Clim. Dynam., 32(2-3), 273-285, doi:10.1007/s00382-008-0467-6, 2009.

Lumpkin, R., Speer, K. G., and Koltermann, K. P.: Transport across $48 \mathrm{~N}$ in the Atlantic Ocean, J. Phys. Oceanogr., 38, 733-752, 2008.

Mahowald, N., Baker, A., Bergametti, G., Brooks, N., Duce, R., Jickells, T., Kubilay, N., Prospero, J., and Tegen, I.: Atmospheric global dust cycle and iron inputs to the ocean, Global Biogeochem. Cy., 19(4), GB4025,10.1029/2004GB002402, 2005.

Maier-Reimer, E. and Hasselmann, K.: Transport and storage of $\mathrm{CO}_{2}$ in the ocean-an inorganic ocean-circulation carbon cycle model, Clim. Dynam., 2, 63-90, 1987.

Maier-Reimer, E.: Geochemical cycles in an ocean general circulation model. Preindustrial tracer distribution, Global Biogeochem. Cy., 7, 645-677, 1993.

Maier-Reimer, E., Kriest, I., Segschneider, J., and Wetzel, P.: The HAMburg Ocean Carbon Cycle Model HAMOCC5.1 Technical Description Release 1.1, in: Berichte zur Erdsystemforschung, Max Planck Institute for Meteorology, Hamburg, Germany, 14, 50 pp., ISSN 1614-1199, 2005.

Marinov, I., Gnanadesikan, A., Toggweiler, J. R., and Sarmiento, J. L.:The Southern Ocean biogeochemical divide, Nature, 441, 964-967, 2006.

Marsland, S. J., Haak, H., Jungclaus, J. H., Latif, M., and Röske, F.: The Max-Planck-Institute global ocean/sea ice model with orthogonal curvilinear coordinates, Ocean Model., 5(2), 91-127, 2003.

Martin, J. H.: Glacial-Interglacial $\mathrm{CO}_{2}$ change: The iron hypothesis, Paleoceanography, 5(1), 1-13, 1990.

Matsumoto, K., Sarmiento, J. L., Key, R. M., Aumont, O., Bullister, J. L., et al.: Evaluation of ocean carbon cycle models with data-based metrics, Geophys. Res. Lett., 31, L07303, doi:10.1029/2003GL018970, 2004.

Matsumoto, K. and Gruber, N.: How accurate is the estimation of anthropogenic carbon in the ocean? An evaluation of the $\Delta \mathrm{C}^{*}$ method, Global Biogeochem. Cy., 19, GB3014, doi:10.1029/2004GB002397, 2005.

Matsumoto, K.: Radiocarbon-based circulation age of the world oceans, J. Geophys. Res., 112, C09004, doi:10.1029/2007JC004095, 2007.

McClelland, J. W., Dery, S. J., Peterson, B. J., Holmes, R. M., and Wood, E. F.: A pan-arctic evaluation of changes in river discharge during the latter half of the 20th century, Geophys. Res. Lett., 33, L06715, doi:10.1029/2006GL025753, 2006.

McDougall, T. J. and Jackett, D. R.: An Assessment of Orthobaric Density in the Global Ocean, J. Phys. Oceanogr., 35, 2054-2075, 2005.

Metzl, N.: Decadal increase of oceanic carbon dioxide in Southern Indian Ocean surface waters (1991-2007), Deep-Sea Res. Pt. II, 8-10, 607-619, doi:10.1016/j.dsr2.2008.12.007, 2009.

Moore, J. K. and Braucher, O.: Sedimentary and mineral dust sources of dissolved iron to the world ocean, Biogeosciences, 5, 631-656, 2008, http://www.biogeosciences.net/5/631/2008/.

Moore, J. K., Doney, S. C., Glover, D. M., and Fung, I. Y.: Iron cycling and nutrient-limitation patterns in surface waters of the World Ocean, Deep-Sea Res. Pt. II, 49, 463-507, 2002.
Najjar, R., Sarmiento, J. L., and Toggweiler, J. R.: Downward transport and fate of organic matter in the ocean: Simulations with a general circulation model, Global Biogeochem. Cy., 6(1), 45-76, 1992.

Nilsen, J., Gao, Y., Drange, H., Furevik, T., and Bentsen, M.: Simulated North Atlantic-Nordic Seas water mass exchanges in an isopycnic coordinate OGCM, Geophys. Res. Lett., 30, 15361539, 2003.

Oberhuber, J.M.: Simulation of the Atlantic Circulation with a coupled sea ice-mixed layer-isopycnal General Circulation Modell. Part I: Modell Description. J. Phys. Oceanogr., 23, 808-829, 1993.

Orr, J.: Global Ocean Storage of Anthropogenic Carbon (GOSAC), EC Environment and Climate Programme (Contract ENV4CT97-0495), Final Report, IPSL/CNRS, France, 129 pp., 2002.

Orre, S., Gao, Y., Drange, H., and Deleersnijder, E.: Diagnosing ocean tracer transport from Sellafield and Dounreay by Equivalent Diffusion and Age, Adv. Atmos. Sci., 25(5), 805-814, 2008

Orre, S., Smith, J. N., Alfimov, V., and Bentsen, M.: Simulating transport of 129I and idealized tracers in the northern North Atlantic Ocean, Environ. Fluid Mech., doi:10.1007/s10652-0099138-3, 2009.

Orsi, A. H., Johnson, G. C., and Bullister, J. L.: Circulation, mixing, and production of Antarctic Bottom Water, Progress in Oceanography, 43, 55-109, 1999.

Oschlies, A., Schulz, K. G., Riebesell, U., and Schmittner, A.: Simulated 21st century's increase in oceanic suboxia by $\mathrm{CO}_{2}-$ enhanced biotic carbon export, Global Biogeochem. Cy., 22, GB4008, doi:10.1029/2007GB003147, 2008.

Otterå, O. H., Bentsen, M., Bethke, I., and Kvamstø, N. G.: Simulated pre-industrial climate in Bergen Climate Model (version 2): model description and large-scale circulation features, Geosci. Model Dev., 2, 197-212, 2009.

Raven, J., Caldeira, K., Elderfield, H., Hoegh-Guldberg, O., Liss, P., Riebesell, U., Shepherd, J., Turley, C., Watson, A., Heap R.,, Banes, R., and Quinn, R.: Ocean acidification due to increasing atmospheric carbon dioxide, The Royal Society, London, Policy document 12/05, ISBN 085403617 2, 68 pp., 2005.

Revelle, R. and Suess, H. E.: Carbon dioxide exchange between atmosphere and ocean and the question of an increase of atmospheric $\mathrm{CO}_{2}$ during past decades, Tellus, IX, 18-27, 1957.

Ridgwell, A. and Hargreaves, J. C.: Regulation of atmospheric $\mathrm{CO}_{2}$ by deep-sea sediments in an Earth system model, Global Biogeochem. Cy., 21, GB2008, doi:10.1029/2006GB002764, 2007.

Sabine, C. L., Feely, R. A., Gruber, N., Key, R. M., et al.: The Oceanic SInk for Anthropogenic $\mathrm{CO}_{2}$, Science, 305, 367-371, 2004.

Sabine, C. L., Key, R. M., Kozyr, A., Feely, R. A., Wanninckhof, R., Millero, F. J., Peng, T.-H., Bullister, J. L., and Lee, K.: Global Ocean Data Analysis Project: Results and Data. ORNL/CDIAC 145, NDP-083, Carbon Dioxide Information Analysis Center, Oak Ridge National Laboratory, US Department of Energy, Oak Ridge, Tennessee, 110 pp., 2005.

Sarmiento, J. L., Gruber, N., Brzesinski, M. A., and Dunne, J. P.: High latitude controls of the global nutricline and low latitude biological production, Nature, 427, 56-60, 2004.

Sarthou, G., Jeandel, C., Brisset, L., Amouroux, D., Besson, T., and Donard, O. F. X.: Fe and $\mathrm{H}_{2} \mathrm{O}_{2}$ distributions in the upper water column in the Indian Sector of the Southern Ocean, Earth Planet. 
Sc. Lett., 147, 83-92, 1997.

Schlitzer, R.: Applying the Adjoint Method for Global Biogeochemical Modeling, in: Inverse Methods in Biogeochemical Cycles, edited by: Kasibhatla, P., Heimann, M., Hartley, D., Mahowald, N., Prinn, R., and Rayner, P., AGU, USA, 107-124, 2000 .

Schneider, B., Bopp, L., Gehlen, M., Segschneider, J., Frölicher, T. L., Cadule, P., Friedlingstein, P., Doney, S. C., Behrenfeld, M. J., and Joos, F.: Climate-induced interannual variability of marine primary and export production in three global coupled climate carbon cycle models, Biogeosciences, 5, 597-614, 2008, http://www.biogeosciences.net/5/597/2008/.

Schuster, U. and Watson, A. J.: A variable and decreasing sink for atmospheric $\mathrm{CO}_{2}$ in the North Atlantic, J. Geophys. Res., 112, C11006, doi:10.1029/2006JC003941, 2007.

Schuster, U., Watson, A. J., Bates, N. R., Corbiere, A., GonzalesDavila, M., Metzl, N., Pierrot, D., and Santana-Casiano, M.: Trends in North Atlantic $\mathrm{fCO}_{2}$ from 1990 to 2006, DeepSea Res. Pt. II, 8-10, 620-629, doi:10.1016/j.dsr2.2008.12.011, 2009.

Semiletov, I., Makshtas, A., Akasafu, S.-I., and Andreas, E. L.: Atmospheric $\mathrm{CO}_{2}$ balance: The role of arctic sea ice, Geophys. Res. Lett., 31, L05121, doi:10.1029/2003GL017996, 2004.

Semtner Jr., A. J.: A Model for the Thermodynamic Growth of Sea Ice in Numerical Investigations of Climate, J. Phys. Oceanogr., 6, 379-389, 1976.

Sillen, L.-G.: Regulation of $\mathrm{O}_{2}, \mathrm{~N}_{2}$ and $\mathrm{CO}_{2}$ in the atmosphere; thoughts of a laboratory chemiste, Tellus, XVIII(2), 198-206, 1966.

Six, K. and Maier-Reimer, E.: Effects of plankton dynamics on seasonal carbon fluxes in an ocean general circulation model, Global Biogeochem. Cy., 10, 559-583, 1996.

Smolarkiewicz, P. K. and Margolin, L. G.: MPDATA: A FiniteDifference Solver for Geophysical Flows, J. Comput. Phys., 140, 459-480, 1998.

Sun, S., Bleck, R., Rooth, C., Dukowicz, J., Chassignet, E., and Killworth, P.: Inclusion of Thermobaricity in IsopycnicCoordinate Ocean Models, J. Phys. Oceanogr., 29, 2719-2729, 1999.
Takahashi, T., Broecker, W. S., and Langer, S.: Redfield ratio based on chemical data from isopycnal surfaces, J. Geophys. Res., 90(C4), 6907-6924, 1985.

Takahashi, T., Sutherland, S. C., Sweeney, C., Poisson, A., et al.: Global sea-air $\mathrm{CO}_{2}$ flux based on climatological surface ocean $p \mathrm{CO}_{2}$ and seasonal biological and temperature effects, Deep-Sea Res. Pt. II, 49, 1601-1622, 2002.

Takahashi, T., Sutherland, S. C., Wanninkhof, R., Sweeney, C., et al.: Climatological mean and decadal changes in surface ocean $p \mathrm{CO}_{2}$, and net sea-air $\mathrm{CO}_{2}$ flux over the global oceans, SOCOVV SymposiumVolume, Deep-Sea Res. Pt. II, 8-10, 554577, doi:10.1016/j.dsr2.2008.12.009, 2009.

Taylor, K. E.: Summarizing multiple aspects of model performance in a single diagram, J. Geophys. Res., 106(D7), 7183-7192, 2001.

Timmermann, R. and Beckmann, A.: Parametrizations of vertical mixing in the Weddell Sea, Ocean Model., 6, 83-100, 2004.

Tjiputra, J. F., Assmann, K., Bentsen, M., Bethke, I., Otterå, O. H., Sturm, C., and Heinze, C.: Bergen earth system model (BCM-C): model description and regional climate-carbon cycle feedbacks assessment, Geosci. Model Dev. Discuss., 2, 845-887, 2009.

Treguer, P., Nelson, D. M., van Bennekom, A. J., DeMaster, D. J., Leynaert, A., and Queguinier, B.: The balance of silica in the world ocean: A re-estimate, Science, 268, 375-379, 1995.

Wanninkhof, R.: Relationship between wind speed and gas exchange over the ocean, J. Geophys. Res., 97, 7373-7382, 1992.

Weiss, R. F.: The solubility of nitrogen, oxygen and argon in water and sea water, Deep-Sea Res., 17, 721-735, 1970.

Weiss, R. F.: Carbon dioxide in water and seawater: The solubility of a non-ideal gas, Mar. Chem., 2, 203-215, 1974.

Wetzel, P., Winguth, A., and Maier-Reimer, E., Sea-to-air $\mathrm{CO}_{2}$ flux from 1948 to 2003: A model study. Global Biogeochem. Cy., 19 , GB2005, doi:10.1029/2004GB002339, 2005.

Whitney, F. A., Freeland, H. J., and Robert, M.: Persistently declining oxygen levels in the interior waters of the eastern subarctic Pacific, Prog. Oceangr., 75, 179-199, 2007.

Winton, M., Hallberg, R., and Gnanadesikan, A.: Simulation of density-driven frictional downslope flow in $\mathrm{z}$-coordinate ocean models, J. Phys. Oceanogr., 28, 2163-2174, 1998.

Zalesak, S. T.: Fully Multidimensional Flux-Corrected Transport Algorithms for Fluids, J. Comput. Phys., 31, 335-362, 1979. 